\title{
TOWARD HIGH-QUALITY DEVELOPMENT IN THE PEOPLE'S REPUBLIC OF CHINA
}

Fan Gang and Zhang Xiaojing

NO. 18

December 2019
ADB EAST ASIA WORKING PAPER SERIES 
ADB East Asia Working Paper Series

\section{Toward High-Quality Development in the People's Republic of China}

Fan Gang and Zhang Xiaojing

No. 18 | December 2019
Fan Gang is from the National Economic Research Institute and Zhang Xiaojing is from the Chinese Academy of Social Sciences. 
(C) 2019 Asian Development Bank

6 ADB Avenue, Mandaluyong City, 1550 Metro Manila, Philippines

Tel +632 8632 4444; Fax +63286362444

www.adb.org

Some rights reserved. Published in 2019.

Printed in the Philippines

Publication Stock No. WPS190585-2

DOI: http://dx.doi.org/10.22617/WPS190585-2

The views expressed in this publication are those of the authors and do not necessarily reflect the views and policies of the Asian Development Bank (ADB) or its Board of Governors or the governments they represent.

ADB does not guarantee the accuracy of the data included in this publication and accepts no responsibility for any consequence of their use. The mention of specific companies or products of manufacturers does not imply that they are endorsed or recommended by ADB in preference to others of a similar nature that are not mentioned.

By making any designation of or reference to a particular territory or geographic area, or by using the term "country" in this document, $A D B$ does not intend to make any judgments as to the legal or other status of any territory or area.

This work is available under the Creative Commons Attribution 3.0 IGO license (CC BY 3.0 IGO)

https://creativecommons.org/licenses/by/3.0/igo/. By using the content of this publication, you agree to be bound by the terms of this license. For attribution, translations, adaptations, and permissions, please read the provisions and terms of use at https://www.adb.org/terms-use\#openaccess.

This CC license does not apply to non-ADB copyright materials in this publication. If the material is attributed to another source, please contact the copyright owner or publisher of that source for permission to reproduce it. $A D B$ cannot be held liable for any claims that arise as a result of your use of the material.

Please contact pubsmarketing@adb.org if you have questions or comments with respect to content, or if you wish to obtain copyright permission for your intended use that does not fall within these terms, or for permission to use the ADB logo.

Corrigenda to ADB publications may be found at http://www.adb.org/publications/corrigenda.

Notes:

In this publication, “\$” refers to United States dollars.

ADB recognizes "China” as the People's Republic of China.

The ADB East Asia Working Paper Series is a forum for stimulating discussion and eliciting feedback on ongoing and recently completed research and policy studies undertaken by the East Asia Department of the Asian Development Bank (ADB) staff, consultants, or resource persons. The series deals with key economic and development problems, as well as conceptual, analytical, or methodological issues relating to project/program economic analysis, and statistical data and measurement. The series aims to enhance the knowledge on Asia's development and policy challenges; strengthen analytical rigor and quality of ADB's country partnership strategies, and its subregional and country operations; and improve the quality and availability of statistical data and development indicators for monitoring development effectiveness.

The ADB East Asia Working Paper Series is a quick-disseminating, informal publication whose titles could subsequently be revised for publication as articles in professional journals or chapters in books. The series is maintained by the East Asia Department.

This paper was prepared as a background study for the preparation of the High-Level Round Table Discussion on the People's Republic of China's transition to high-quality development, coordinated by the Asian Development Bank. 


\section{CONTENTS}

\section{TABLES AND FIGURES}

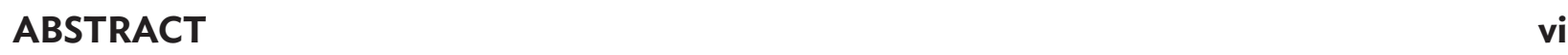

ABBREVIATIONS vii

$\begin{array}{lll}\text { I. INTRODUCTION } & 1\end{array}$

II. INSTITUTIONAL REFORM AND TRANSFORMING TO A MODERN 2 ECONOMIC SYSTEM

III. INNOVATIVE DEVELOPMENT

A. Current Situation and Problems 3

B. Invention Patents 3

C. Transformation of Innovation Achievements 5

D. Basic and Applied Research

E. Output of International Academic Papers

F. Recommendations to Advance Innovation and Development $\quad 7$

$\begin{array}{llr}\text { IV. } & \text { BALANCED DEVELOPMENT } & \mathbf{8}\end{array}$

A. Current Situation and Problems 8

B. Industrial Structure $\quad 9$

C. Urban-Rural Structure

D. Regional Structure $\quad 13$

E. Recommendations to Promote Balanced Development 14

$\begin{array}{ll}\text { V. GREEN DEVELOPMENT } & 16\end{array}$

A. Current Situation and Problems 16

B. Prospects for Green Development 19

C. Recommendations to Advance Green Development 21

VI. OPEN DEVELOPMENT $\quad 22$

A. Current Situation and Problems 22

B. Structure, Quality, and Benefits of Capital Inflows

C. Deficit and Openness of the Services Trade 25

D. Recommendations for Further Opening Up 26

1. Improve the Foreign Investment Environment $\quad 27$

2. Attract More Foreign Investment and Expand Imports 27

3. Progressively Introduce Zero Tariffs for Manufacturing 27

4. Open up the Services Sector 28

5. Strengthen Trade Policy Compliance $\quad 29$ 
$\begin{array}{ll}\text { VII. SHARED DEVELOPMENT } & 29\end{array}$

A. Current Situation and Problems $\quad 29$

B. Changes in Income Distribution 30

C. Equal Opportunity $\quad 31$

D. Equalization of Public Services 32

B. Policy Recommendations for Promoting Shared Development 32

VIII. FIVE-YEAR PLANS USING THE 1+N APPROACH 33

A. National Master Plan $\quad 34$

B. Department and Local Work Plans

$\begin{array}{ll}\text { REFERENCES } & 36\end{array}$ 


\section{TABLES AND FIGURES}

\section{TABLES}

1 Emissions of Wastewater and Waste Gas Pollutants 19

2 Wealth Inequality between the People's Republic of China and the United States (\%) 31

3 Urban Household Income Mobility (\%) 31

\section{FIGURES}

1 Granted Patents, 1995-2016 (million) 4

2 Proportion of Invention Patents Granted Overseas, 1995-2016 (\%) 5

3 Research Spending, 1995-2016 6

4 Proportion of Experimental Development, Applied Research, Basic Research, 6 and Development Spending to Gross Domestic Product, 1998-2016 (\%)

5 Agriculture, Industry, and Services Value Added as a Proportion of Gross Domestic Product, 9 1978-2016 (\%)

6 Share of Manufacturing Value Added in Gross Domestic Product, 1978-2016 (\%) 10

7 Share of the Services Sector's Value Added in the Gross Domestic Product of Major Economies (\%) 11

8 Proportion of Urban Population to Total Population, 1960-2016 (\%) 12

9 Per Capita Disposable Income of Urban versus Rural Residents, 1978-2016 12

10 Gross Domestic Product per Capita in Eastern and Central Regions Compared 13 with the Western Region, 2003-2016

11 Carbon Emission in Major Economies, 1978-2014 16

12 Fuel Consumption Equivalent per Unit of Gross Domestic Product in Major Economies, 17 1990-2014 (kgoe)

13 Structure of Energy Consumption in the People's Republic of China, 2000-2016 (\%) 18

14 Structure of Energy Consumption in the United States, 2015 (\%) 18

15 Carbon Emissions, 1978-2014 (100 million tons) 20

16 Oil Equivalent of Energy Consumption in the People's Republic of China (100 million tons) 20

17 Trade Dependence of the People's Republic of China, 2000-2016 (\%) 22

18 Trade Dependence of the United States, 2005-2017 (\%) 23

19 Inward and Outward Foreign Direct Investment, 1995-2017 (\$ billion) 23

20 Foreign Direct Investment by Sector, 2007 versus 2016 (\%) 24

21 Services Trade Imports and Exports, 2005-2017 (\$ billion) 25

22 Tourism Trade, 2005-2017 (\$ billion) 26

23 Effective Tax Rates on Manufactured Products in Major Economies, 1998-2016 28

24 Gini Coefficient, 2003-2017 30 


\begin{abstract}
This paper covers three areas that will be vital for the People's Republic of China (PRC) to transition to high-quality development: advancing institutional reform, practicing the new development philosophy, and changing the approach to how the country's five-year plans are drawn up. Institutional reform highlights the quality of government in which state capacity is necessary for setting and realizing national objectives. Here, rule of law and accountability are crucial to constrain the government activities. The new development philosophy defines the high-quality development in which innovation and inclusive development should be focused, and the role of the market and the private economy in this process. For the PRC's five-year plans, the paper proposes a new top-down approach in which government departments and regional authorities contribute to national goals rather than the current practice of framing national master plans in terms of the individual goals of these entities.
\end{abstract}

Keywords: high-quality development, new development philosophy, five-year plans, institutional reform, People's Republic of China 


\title{
ABBREVIATIONS
}

\author{
FDI foreign direct investment \\ GDP gross domestic product \\ PRC People's Republic of China \\ SOE state-owned enterprise \\ WTO World Trade Organization
}





\section{INTRODUCTION}

This paper examines three key areas that will be vital for the People's Republic of China (PRC) to transition to high-quality development: advancing institutional reform, practicing the new development philosophy, and reforming the approach to development planning. Institutional reform highlights the quality of government. The core of high-quality development in the PRC, which supersedes the highspeed growth phase, is a transformation in the mode of development where the quality of government is critical. This has three dimensions: state capacity, rule of law, and accountability. Without strong state capacity, it is difficult to achieve development goals. But there will also be undesirable consequences if the objectives of these goals are inappropriate or lack necessary checks. That is why the two other dimensions of government quality-rule of law and accountability-are crucial for containing state capacity.

The new development philosophy defines development from five aspects: innovative, coordinated, green, open, and shared. In the early stage of development, governments can play a positive role in realizing a country's "second-mover" advantage by helping collect and channel established "frontier technology" to accelerate development. But as the scope for "within-frontier" innovation shrinks, the government's comparative advantage in this area declines correspondingly. At this point, innovation should be largely dependent on the market mechanism and the private economy. Here, the PRC government should focus on protecting intellectual property rights and profits from innovation. To promote coordinated development, it is vital to resolve distortions and imbalances at origin. The root cause of distortions is largely more government intervention rather than less. To solve this problem, it is essential to give full play to the decisive role of the market. The key to advancing green development will be adjusting the structure of the economy and the energy mix, and the industrial layout. It will involve cultivating and strengthening energy conservation, environmental protection, and clean energy industries; as well as promoting comprehensive resource conservation and recycling. In tandem with this, efforts to set up a market mechanism for ecological and environmental governance need to be accelerated.

Open development includes improving the business environment, strengthening trade policy compliance, promoting regional cooperation and integration, and enhancing the bilateral market openness. Grasping the learning opportunities from other countries will be crucial for the PRC in the medium term. Shared development emphasizes equal opportunities and universal high school education. Shared development refers not only to the equalization of basic public services, such as targeted poverty alleviation, inclusive finance, education, and social security, but also broader social and political participation.

The transition to high-quality development will involve many policy challenges. A major characteristic of this transition is that development challenges will become more complex and cross-sectoral, and less amenable to compartmentalization. This will require a change in the approach to development planning. This paper proposes that a $1+\mathrm{N}$ planning approach is used for drawing up the PRC's five-year plans. Here, the National Development and Reform Commission prepares a top-down general strategic plan, setting out an overall vision for national development, including the main objectives and strategic tasks for the government as a whole. At this point tasks are not be assigned to individual departments. Once the national master plan is approved, the $\mathrm{N}$ number of government departments will be tasked with preparing department plans that reflect the contribution of each department to national goals (rather than one aspect of them). The department plans and fiscal arrangements should be integrated

with budgets allocating resources according to planned investments and public services. Adopting an integrated cross-sectoral planning process such as this will enable the cross-department synergies needed for the transition to high-quality development. 


\section{INSTITUTIONAL REFORM AND TRANSFORMING TO A MODERN ECONOMIC SYSTEM}

The core of high-quality development is improving the quality and efficiency of production, and meeting people's expectations for a better life. This pattern of development includes steady income growth and consumption, economic and social stability, improving the environment, and inclusiveness and equality, among other things.

The major challenge facing the PRC in the medium term will be to transform the mode of developmentand particularly to let the market play a decisive role in the allocation of resources. Government intervention remains strong in the absence of well-functioning regulatory governance. This has restricted improvement of economic efficiency and caused the government to bear various kinds of explicit and implicit responsibilities, especially debt, as well as the aggravated moral hazard of various economic agents. This has led to distortions and resource misallocation. Substantive market-oriented reforms playing the role of government better are the key to resolving these risks and distortions. To accomplish this, a modern economic system needs to be built with an effective market mechanism, vigorous microeconomic entities, and proper macroeconomic control.

An effective market mechanism advances the reform of factor liberalization and lets the market decide price formation, so that resources are allocated according to supply-demand dynamics. The basis for an effective market mechanism is reduced government intervention, strengthened government functions to enhance and safeguard the market, and decisive role of markets in allocation of resources. An effective market mechanism ensures the free entry and exit of economic agents. A smooth entry mechanism will break up monopolies and promote competition; an effective exit mechanism will invalidate inefficient production capacity; and zombie firms will be cleared by the market. Above all, an effective market mechanism allows for risks to be shared by market players so that the many risks arising from government intervention, and the hidden guarantees behind them, will not be borne by the government alone.

To activate market participants, the property rights system needs perfecting, as does the market-oriented allocation of production factors to achieve the effective incentive of property rights, full factor mobility, flexible price responsiveness, and a level playing field. The PRC's private economy, mostly small- and medium-sized enterprises, contributes $50 \%$ of tax revenue, $60 \%$ of gross domestic product (GDP), $70 \%$ of technological achievements and their transfers, $80 \%$ of employment, and $90 \%$ of enterprises. It follows that a modern market system cannot be built without the active participation of private economic agents. The latter should play a larger role in driving economic growth and innovations in the PRC in particular. A clear definition and strong protection of property rights will be fundamental for market players. However, there are still many problems getting in the way of achieving this, particularly the use of public power to infringe on private property rights, and the illegal seizure of frozen property of private firms. Factor mobility involves reforms to the land system and the household registration system, and substantial progress on both must be made in the medium term. Achieving fair competition will require accelerating reforms of state-owned enterprises. In the PRC, most monopolistic and zombie firms are owned by the state. Monopolies reflect discrimination at the entry stage; zombie firms reflect discrimination in the exit process.

Having an effective stabilization policy is essential to let the government do its job effectively, but this must also have limits. The ideal stabilization policy is where its existence is not perceived by the people (so-called work silently). Big or small economic events-business cycles and volatility, for example-cannot be solved by stabilization policies alone. As a form of government intervention in the market, stabilization policy is based on respect for and belief in the market. It cannot be used to 
tackle all economic problems. Recognizing this is the basis for understanding the relationship between the government and the market. The stabilization policy in the "new era" of economic development is to take "market determinism" as the basic starting point to advance market-oriented reforms, tamp the micro-foundation of macro control, improve the policy transmission mechanism, and rely more on market-oriented means to regulate the economy.

In the stage of high-quality development, the government's main policy objective is not to participate directly in market competition and economic construction. Rather, it is to create an institutional environment for the market's fair and effective functioning, to ensure coordinated economic development, and to provide corresponding public services. Olson (2000) proposed that governments should contribute to "market incentive" - that is, under the rule of law, governments should help develop and improve the market system, avoid special interest groups forming, and prevent the distorted allocation of resources. This does not mean that smaller government is better government. The PRC should pursue high-quality development on the basis of its own experience and characteristics, especially from the reform and opening-up phases since the late 1970s. This is so that the government can have sufficient, efficient, and sustainable state capacity to achieve its goals for high-quality development while respecting micro-individuals. The quality of government has three dimensions: state capacity, rule of law, and accountability. Without sufficient state capacity, it is difficult to achieve development goals. But if the development objective is inappropriate or lacks necessary restraints, the stronger the state capacity, the more serious are the undesirable consequences. That is why the other two dimensions of government quality_rule of law and accountability_are crucial to contain state capacity.

\section{INNOVATIVE DEVELOPMENT}

\section{A. Current Situation and Problems}

High-quality development requires that the driving force of the PRC's economic development shifts from being factor-driven to innovation-driven. Some progress has been made in building innovation capacity, but there is still a big gap compared with developed countries.

\section{B. Invention Patents}

The number of invention patents in the PRC has grown rapidly since around the start of the 2000s, but progress has been slow in improving their quality. An invention patent is a new technical proposal for a product, method, or improvement, and these patents are an internationally accepted core indicator that reflects the level of technology with intellectual property rights and independent innovation. From 2013 to 2016 , the number of invention patents granted in the PRC rose from 207,699 to 404,208, a 94.6\% increase. In the same period, the proportion of invention patents to the total number of patents granted rose from $15.8 \%$ to $23.1 \%$, an average annual increase of 2.4 percentage points.

The Thirteenth Five-Year Plan for National Scientific and Technological Innovation (2016-2020) explicitly states that national scientific and technological innovation capacity should be greatly increased in the plan period, and that the number of invention patents per 10,000 people should increase from 6.3 to 12.0 items. By 2025, the number of invention patents granted, and the proportion of invention patents to the total number of patents granted, is expected to continue growing rapidly. It is possible that the number of invention patents granted will double in the medium term. 
According to the World Intellectual Property Organization, the PRC ranked first in the world in applying for invention patents for 6 consecutive years since 2011. In 2016, the PRC had more patent applications than the total of Europe, Japan, the Republic of Korea, and the United States, accounting for $42.8 \%$ of the world's total. In 2012, the PRC's intellectual property exports accounted for only $0.36 \%$ of the world's total (42.9\% in the United States and 11.0\% in Japan). From 2003 to 2012, the PRC's trade deficit in intellectual property increased from $\$ 3.4$ billion to $\$ 16.7$ billion, with an average annual growth rate of $19.2 \%$. Figure 1 shows the patent trend since the mid-1990s.

Figure 1: Granted Patents, 1995-2016 (million)

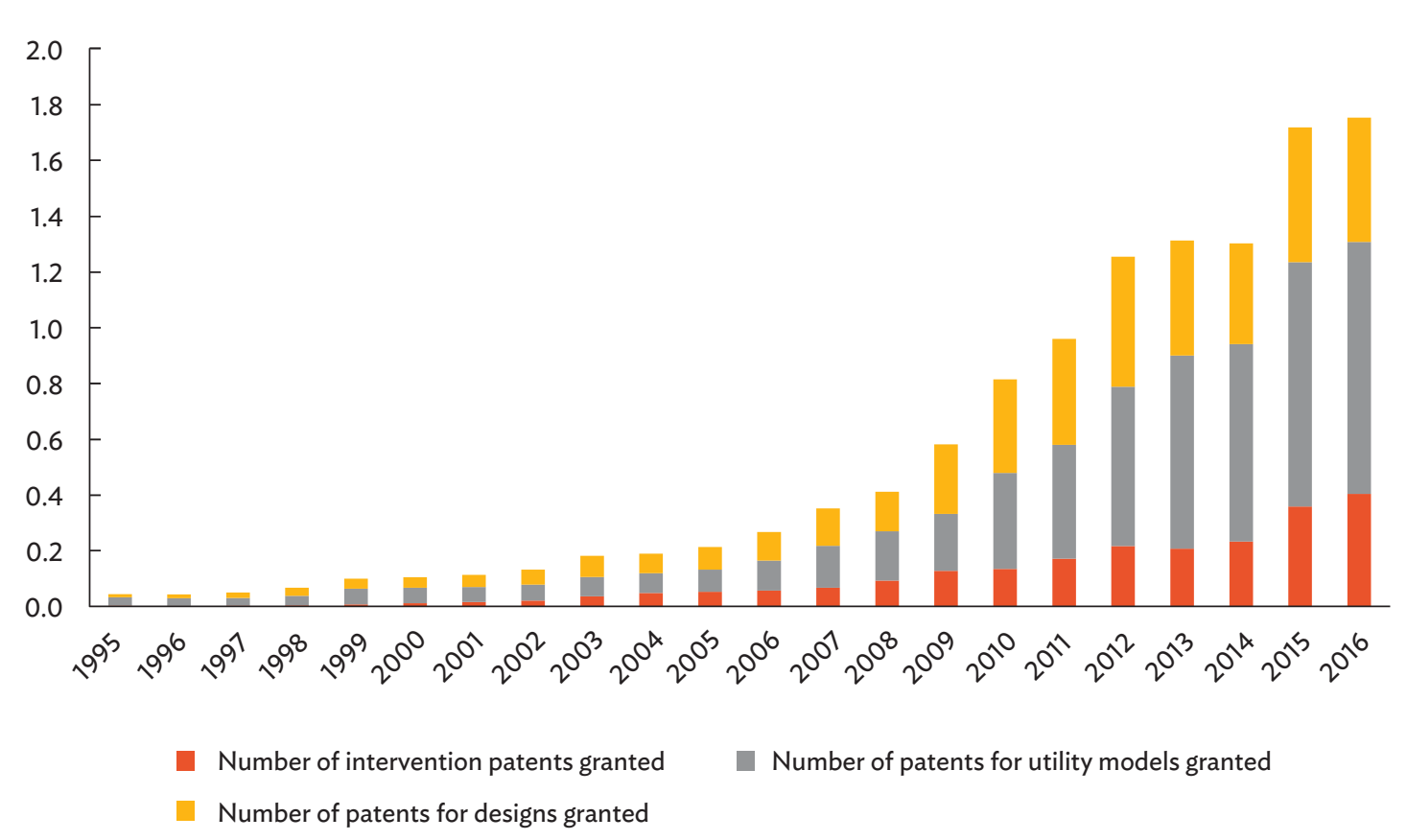

Source: National Bureau of Statistics.

Figure 2 shows that the proportion of invention patents granted abroad in the total number of invention patents nationwide fell from $72.7 \%$ in 2002 to $25.3 \%$ in 2016 . Although the quality of innovation in the PRC is improving, the country still has far to go before it is a world leader in invention patents.

Because the quality of PRC patents filed internationally is examined by foreign patent offices, a horizontal comparison of the number of international patents filed (or granted) is a more accurate gauge of the quality of a country's patents. Data from the Patent Cooperation Treaty on the management of intellectual property worldwide show the PRC had 13.8 international patent applications under the treaty per million people in 2012, which is low by international comparison. Even the United Kingdom, which shows a tendency for declining innovation, had 77.3 million international patent applications per million people in that year, 5.5 times higher than the PRC. Japan, which has a higher average population density than the PRC, was at 341.2-24 times higher than the PRC. This shows that the surge in the number of patents in the PRC should be viewed with caution. 
Figure 2: Proportion of Invention Patents Granted Overseas, 1995-2016 (\%)

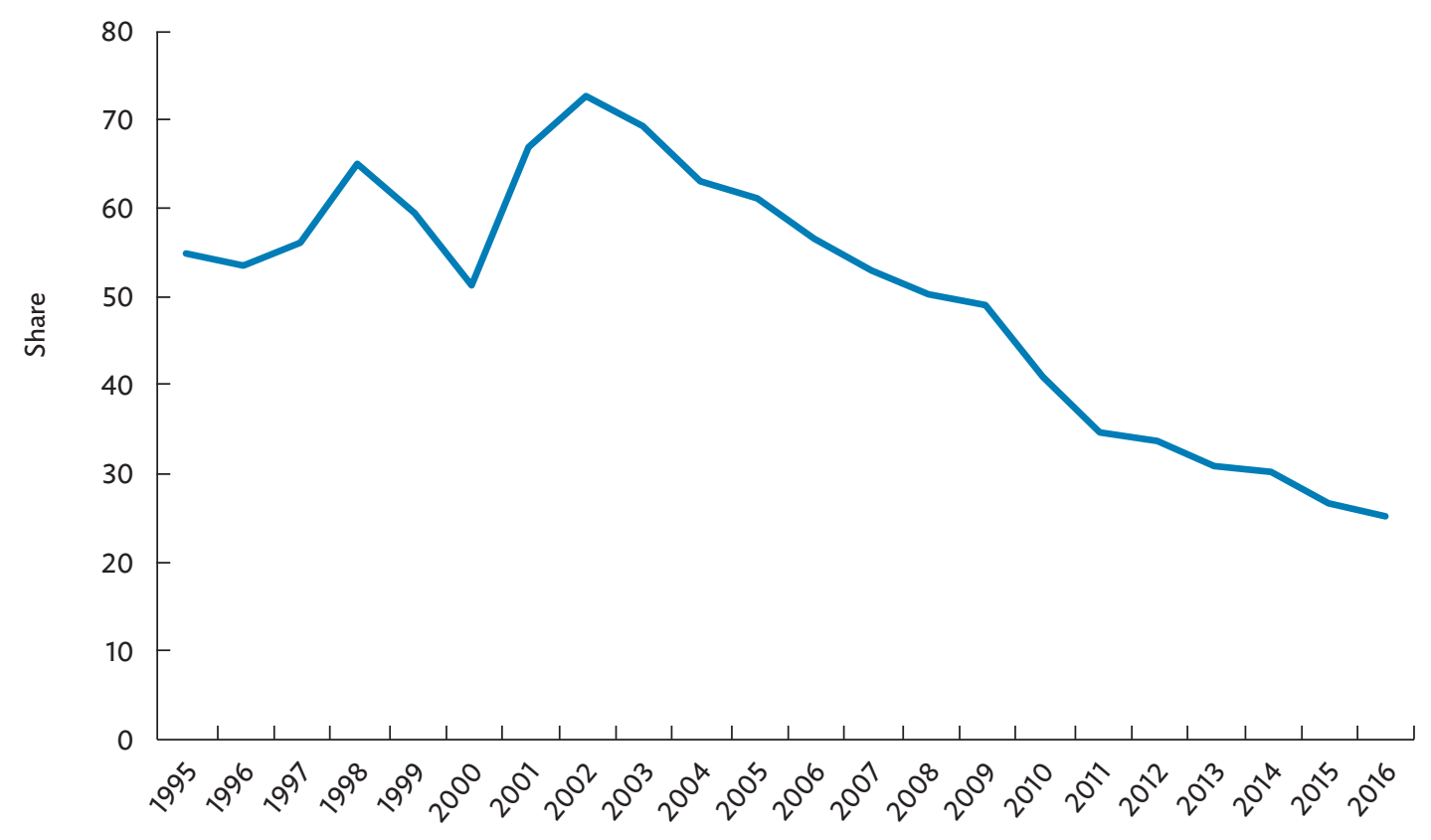

Source: National Bureau of Statistics.

\section{Transformation of Innovation Achievements}

Innovation is the systematic process of transformation of inputs in scientific research to the outputs of innovative scientific and technological achievements, and then into economic benefits. The innovation process can be divided into two stages. The first ranges from inputs in scientific-research investment for realizing scientific and technological achievements. In other words, the ability to reach the independent innovation stage. The second stage is the realization of scientific and technological achievements, and transforming them into economic benefits. This indicator in the Thirteenth Five-Year Plan is clearly defined and is expected to reach $60 \%$ in 2020, 4.7 percentage points higher than in 2015. This indicator in Japan, the United States, and other major developed countries is at about $80 \%$. The contribution of scientific and technological progress in the PRC is expected to reach about 65\% by 2025.

\section{Basic and Applied Research}

The main indicator to measure basic and applied research is the proportion of research spending to GDP. The Thirteenth Five-Year Plan for National Science and Technology Innovation states that research and experimental development funds should be increased from 2.1\% in 2015 to 2.5\% in 2020. These funds include spending on basic and applied research, and experimental development. Figure 3 shows the PRC's research spending has increased noticeably since the end of the first decade of the 2000 s. Figure 4 shows the proportion of research spending to GDP has been increasing since the mid-1990s, reaching $2.1 \%$ in 2016. For its part, the United States has maintained a long-term spending target of at least $2.5 \%$. 
Figure 3: Research Spending, 1995-2016 (10 billion yuan)

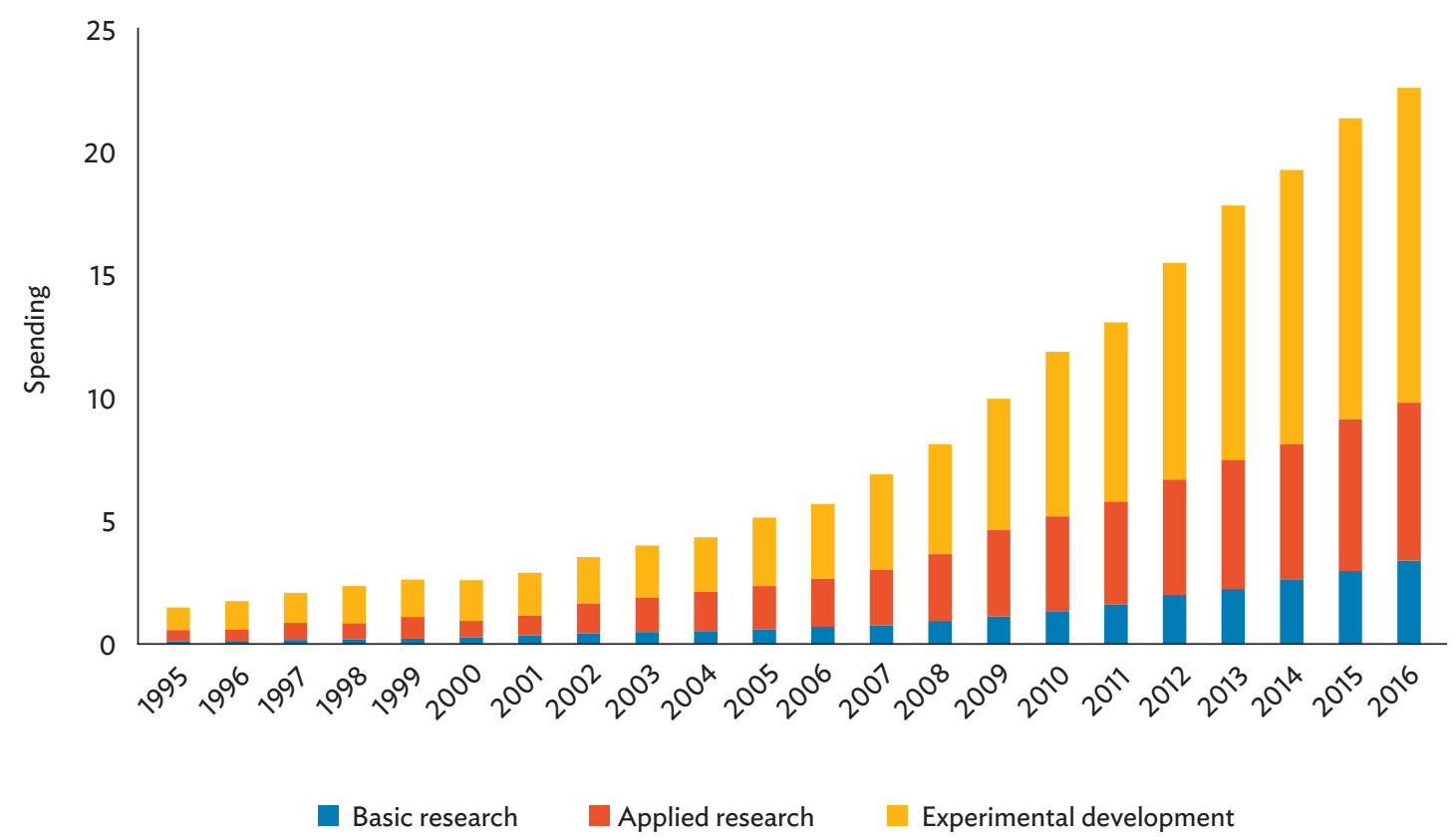

Note: Data presented in this figure refers to the yuan as the currency unit used in the People's Republic of China. Source: National Bureau of Statistics.

Figure 4: Proportion of Experimental Development, Applied Research, Basic Research, and Development Spending to Gross Domestic Product, 1998-2016 (\%)

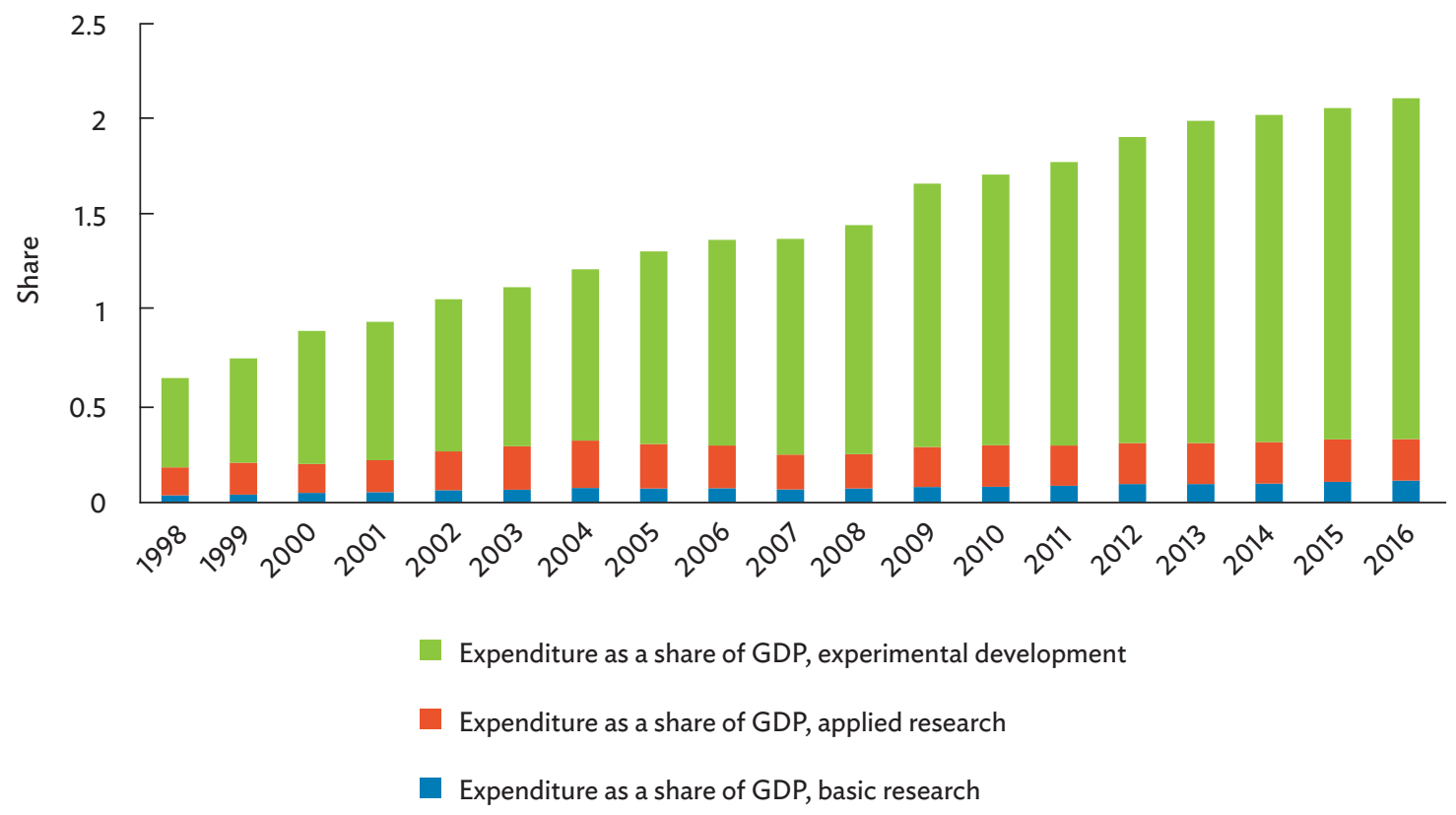

GDP = gross domestic product.

Source: National Bureau of Statistics. 


\section{E. Output of International Academic Papers}

The level of basic scientific research determines the potential and subsequent efforts of national technological innovation. The number of scientific papers indexed in the Science Citation Index and Social Sciences Citation Index are an essential measure of the level of basic research in a country. By 2011, the PRC's output of international academic papers had risen to the second highest in the world after the United States. Most scholars who publish papers with high citation rates are influential academic leaders in their fields. These rates are an important measure of the quality of a country's scientific papers and its basic scientific research. In 2014, the output of highly cited papers in the PRC ranked fourth in the world, after the United States, the United Kingdom, and Germany. But the gap between the PRC and developed countries is still enormous in the number of authors cited per million population. The output of highcitation papers per capita in the PRC is less than $5 \%$ of the papers produced in the United Kingdom and the United States, and less than 10\% of those in Germany and France (Thomson Reuters 2014).

Innovation and development in the PRC still face many problems and challenges. Basic scientific research is insufficient, and the private sector does not pay enough attention to basic research. The country lacks original achievements, basic technology and process capabilities, machine tools, highend chips, basic software and hardware, development platforms, and basic algorithms, electronic components, and materials. The problem here is that core technologies in the PRC are controlled by other countries, a situation that has not fundamentally changed for many years. The PRC's technology research and development has not fully focused on the bottlenecks and needs of industrial development. The PRC is not cooperating enough with science and technology in a global perspective, and its ability to transform scientific and technological achievements is not strong. The country's science and technology management system is not able to meet the needs for building a world power in science and technology. Many important science and technology system reforms have not yet been implemented, and the links between science and technology innovation policies and economic and industrial policies is not strong. Against this backdrop, the mechanism and the environment for society as a whole to encourage innovation needs to be improved.

\section{F. Recommendations to Advance Innovation and Development}

The following recommendations are offered to advance innovation and development:

(i) Rethink the government's role in innovative development. In the early stages of development, the government can help with establishing channels of knowledge and experience sharing with foreign counterparts while enhancing the intellectual property rights (IPR) policy framework and practices. The government then needs to determine the technical route, mobilize resources, and advance the industrialization of technological invention. It should focus on building the infrastructure and creating an institutional environment conducive to innovative development when the following conditions are met: (a) the second-mover advantage shrinks gradually, (b) the uncertainty of technological innovation in the frontier increases, and (c) the government's ability to collect information and make correct decisions decrease markedly. The government should focus on building an ecosystem and infrastructure that is conducive to innovation and development rather than concentrate on specific strategic industries.

(ii) Further strengthen intellectual property rights. This should especially be for judicial protection. To this end, the State Council's Outline of the National Strategy of InnovationDriven Development and Some Opinions of the State Council on Accelerating the Construction of an Intellectual Property Power under the New Situation need to be fully implemented, as does the spirit of the State Council Standing Committee. The government should continue to increase the protection of intellectual property rights, especially judicial protection; increase the number of specialized courts and judges of intellectual property rights; pilot the implementation of tort liability infringement and the punitive tort 
compensation system; increase the cost of infringement and the benefits of innovation; and combine legal remedies with economic levers, thus truly stimulating the innovation motivation and vitality of various innovation entities, especially enterprises.

(iii) Promote quality innovation. This involves changing the pattern of scientific and technological innovation from quantitative growth to qualitative improvement, and establishing an index and policy system that meet the requirements of high-quality development. Five-year plans need to be calibrated so that they can promote qualitative improvement and incorporate more indicators reflecting patent quality and market value, for example, indicators for patent technology trading, licensing income, and intellectual property exports. The government at all levels but especially local government should stop taking special measures to increase the number of patents. They should also cancel rankings that use the number of patents as the main indicator. Financial support for patent application fees needs to be significantly reduced or eliminated, so that patent applications really become a market behavior. The only exception should be giving a certain amount of patent application grants or purchase service subsidies to "zero patent" small- and medium-sized enterprises in the entrepreneurial stage. This is to help these firm enhance their intellectual property awareness and management capacity. The government should reexamine its policies for research and development, taxation, introducing talents, the household registration system, and education; and eliminate unreasonable standards, qualification requirements, and preferential treatment, especially those linked to the number of patents.

(iv) Promote the role of the private economy in innovation. Innovation needs incentives. This means that successful innovators can get monopolized profits, and failed innovators may suffer big losses or go bankrupt. In this sense, private enterprises are far more successful than state-owned enterprises (SOEs). Because SOEs in the PRC benefit from various preferential policies, they operate well without innovation. And it is not easy for an SOE to go bankrupt since even zombie firms can get subsidies. But innovators in SOEs are not sufficiently motivated, since they cannot get the corresponding innovation benefits. The PRC also has more cutting-edge technologies than imitation technologies, therefore future innovations face more uncertainty and require more trial and error. At this point, private enterprises are much stronger than SOEs, because they are more innovation-motivated and more able to bear the risk of failure. Thus, the role of private economy should be emphasized and promoted in the national innovation system.

\section{BALANCED DEVELOPMENT}

\section{A. Current Situation and Problems}

The PRC has long been on a catch-up path, which has often led to unbalanced development. Continuing on this path will inevitably lead to more uneven and uncoordinated development among government departments, industries, and regions. At the PRC's current stage of development, the country needs to run faster to put the catching-up path behind it. In the deliberations on how to do this, not enough attention has been paid to socioeconomic distortions, imbalances, and contradictions. 


\section{B. Industrial Structure}

Since the late 1970s, the PRC has experienced rapid industrialization with the goal of catching up and even surpassing developed countries. Rapid industrialization resulted in a large number of economic resources, such as labor, capital, and land being shifted from low-productive agriculture sectors to high-productive industries and the tertiary sectors serving them. The shift significantly increased the efficiency of resource allocation-a common experience of developing countries as they try to achieve economic take-off and catch-up (Chenery, Robinson, and Syrquin 1986; Lin 2014). As Figure 5 shows, the proportion of agricultural value added in GDP declined from nearly $30 \%$ since the reform and opening-up in 1978, to less than 10\% since 2009.

Figure 5: Agriculture, Industry, and Services Value Added as a Proportion of Gross Domestic Product, 1978-2016 (\%)

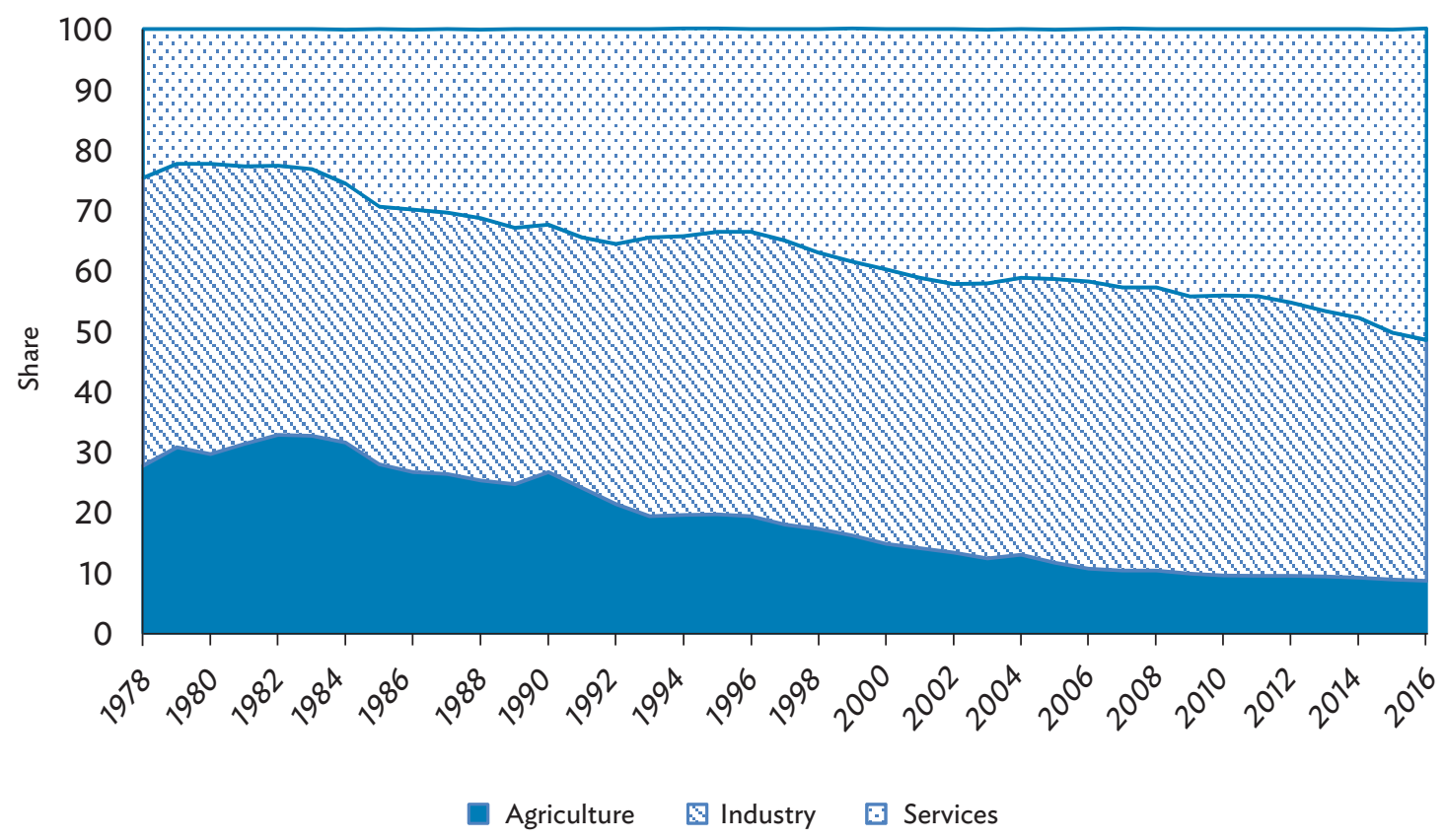

Source: National Bureau of Statistics.

The figure shows the PRC's industrialization process is not directly reflected in the expansion of industry itself, but rather by the upgrading and widening of the industrial system and its deep integration into the international division of labor. In fact, the proportion of industrial value added fell from 48\% in 1978 to less than 40\% in 2016. Manufacturing, industry's most competitive sector, illustrates this point (Figure 6): its share in GDP fell from $40 \%$ to less than $30 \%$ in this period. (Even so, the relative size of the PRC's manufacturing industry is significantly bigger than other large economies, and more than twice that of the United States.) Because of the structure of the PRC's industrial base, its resource endowments, and other factors, this feature will continue for at least the medium term of 5-10 years. Manufacturing, meanwhile, will continue to heavily determine the path of the PRC's future growth. The sector is the most important source of technological progress from the international division of labor. 
Figure 6: Share of Manufacturing Value Added in Gross Domestic Product, 1978-2016 (\%)

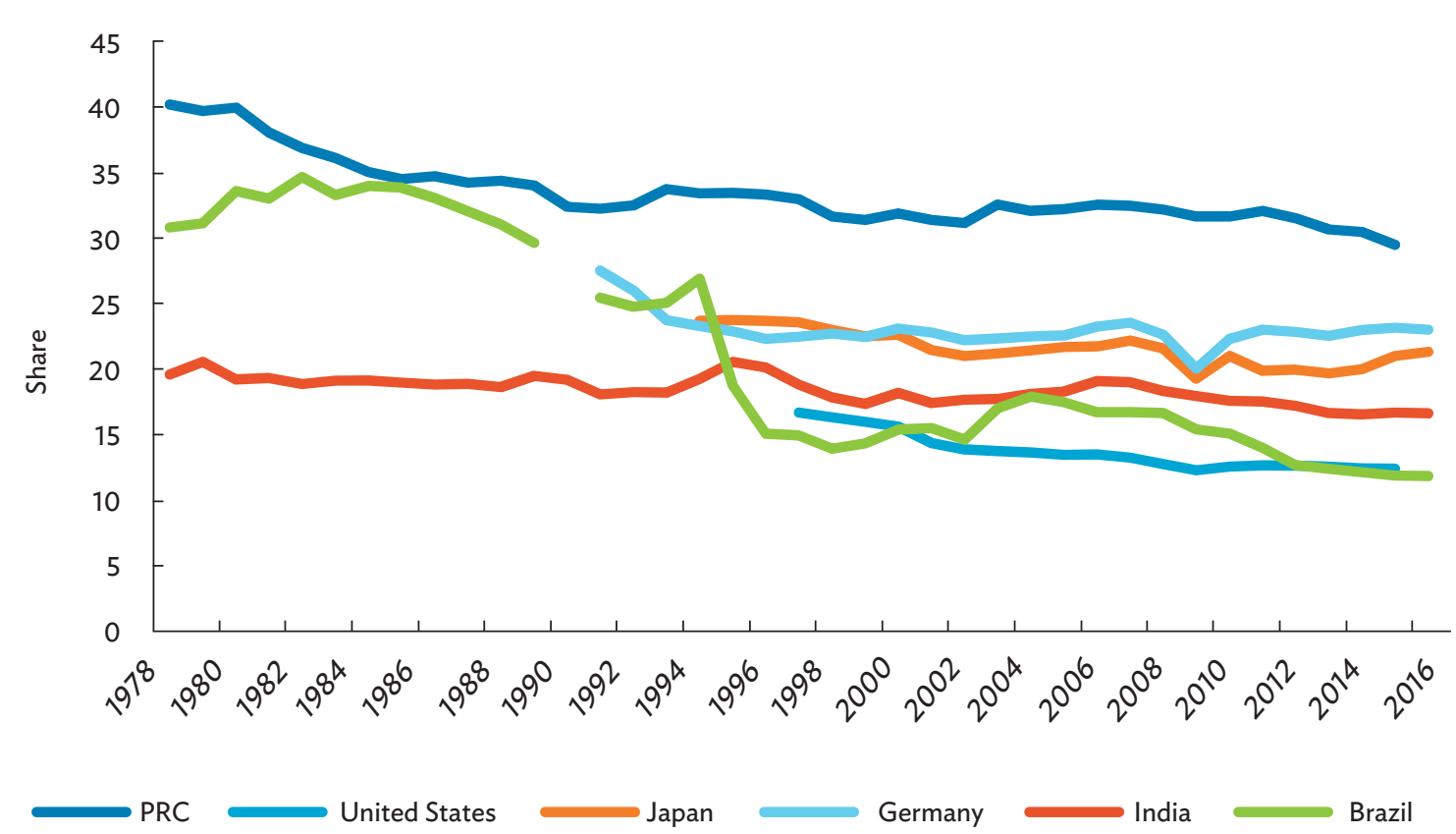

PRC = People's Republic of China .

Source: World Bank. World Development Indicators. https https://data.worldbank.org/indicator/NV.IND.MANF.ZS (accessed_08 December 2018).

Going by the growth and decline of agriculture, industry, and services, the PRC's industrial structure is increasingly changing in favor of the services sector. As Figure 5 shows, the proportion of value added in services was only 25\% of GDP in 1978. By 2012, services had overtaken industry as the largest industrial sector, rising to $52 \%$ of GDP in 2016, more than double that in 1978. It should be noted that the PRC is not alone in this kind of unbalanced development in its services sector, which is reflected internationally. Figure 7 shows the rapid expansion of services in major economies. The difference with the PRC is that although services have rapidly expanded in most other major economies, the proportion of services to GDP has risen at the same pace since the 2008 global financial crisis, and there is still a significant gap-of 20-30 percentage points-in the PRC (and India) with the level of the three developed countries in Figure 6.

The PRC's services sector will likely continue to rapidly expand in the medium term. How to coordinate the relationship between services - and especially financial services - and agriculture, and how to improve the efficiency of the services sector and its degree of openness, will be the future focus of industrial policy. It must also be emphasized that, as noted earlier, there are no simple criteria for "coordination," especially for industrial structure. A single optimal industrial structure that fits all countries does not exist. Brazil and the United States, both at very different levels of development, have large services sectors. India's services sector has long been larger, in relative terms, than the PRC's. In addition, the relative size of the services sector in Germany and Japan is smaller than the PRC's, but significantly larger than Brazil, India, and the United States. In the process of coordinating the development of various industries, the advantages and disadvantages of different structures should be considered in combination with resource endowments, comparative advantages, and efficiency differences between industries. 


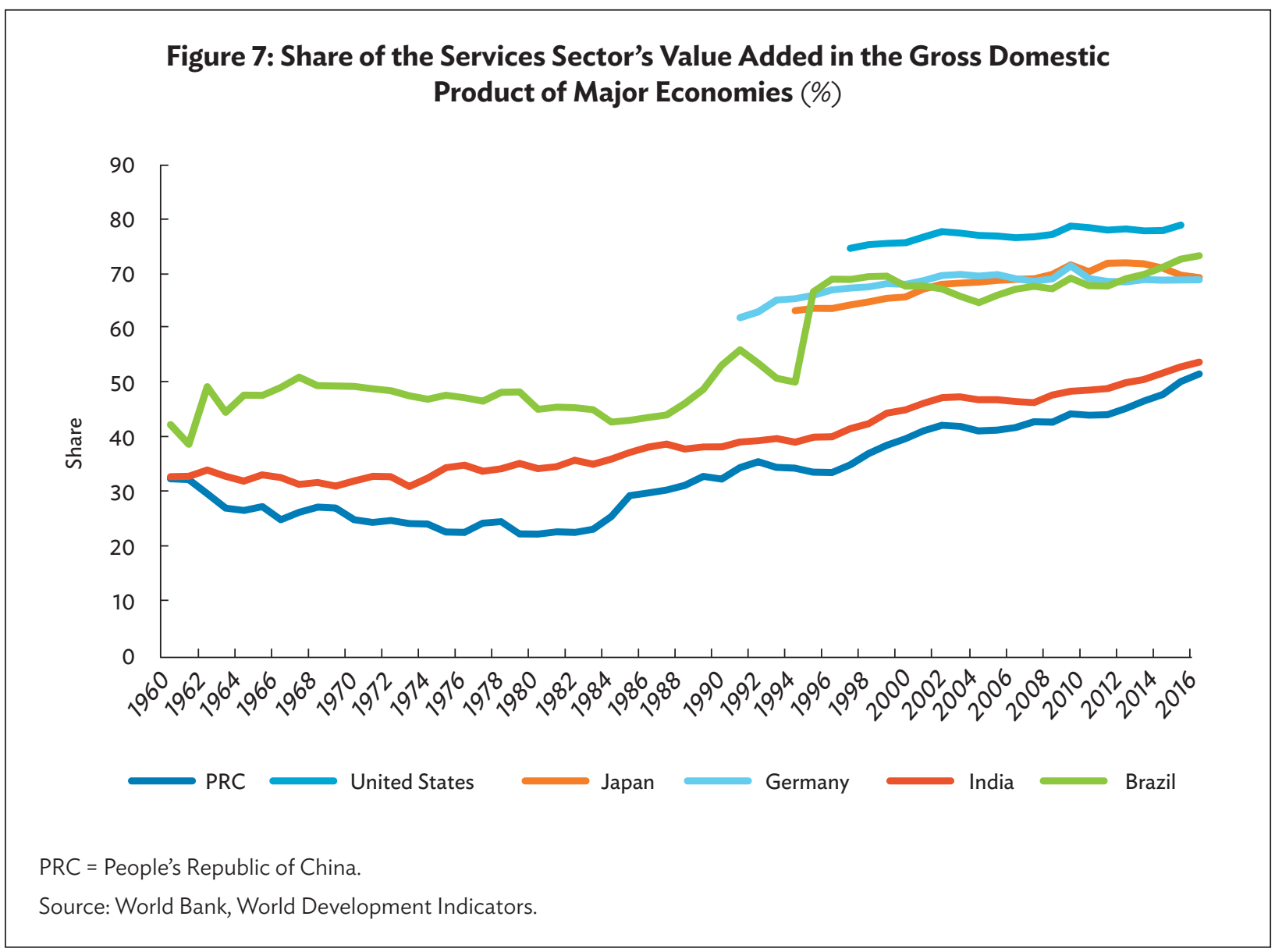

\section{Urban-Rural Structure}

The characteristics and trends of the PRC's industrial structure have directly led to changes in the population distribution in urban and rural areas (as both consumers and producers). These changes have become more pronounced since the mid-1990s. The size of the urban population has continued to rise, exceeding the rural population for the first time in 2011 (Figure 8). Yet, many new urban residents do not enjoy the same public services as the original residents. This is especially so for education, health, social security, and affordable housing. And new urban residents are, to an extent, still seen as "rural residents."

Since the rural reforms of the early 1980s, the income gap between urban and rural residents has increased from 1.8 times in 1983 to 3.3 times in 2009 (Figure 9). Although the ratio has stabilized and even declined in recent years, it is still quite high-at 2.7 times in 2016. This reflects not only differences in welfare, which includes consumption capacity and the level of public services under the dual economic and social structure, but also the difference in productivity between rural and urban areas. Since 2013, the income survey standards for urban and rural residents have been adjusted, but they are not entirely comparable to those of the previous period. 
Figure 8: Proportion of Urban Population to Total Population, 1960-2016 (\%)

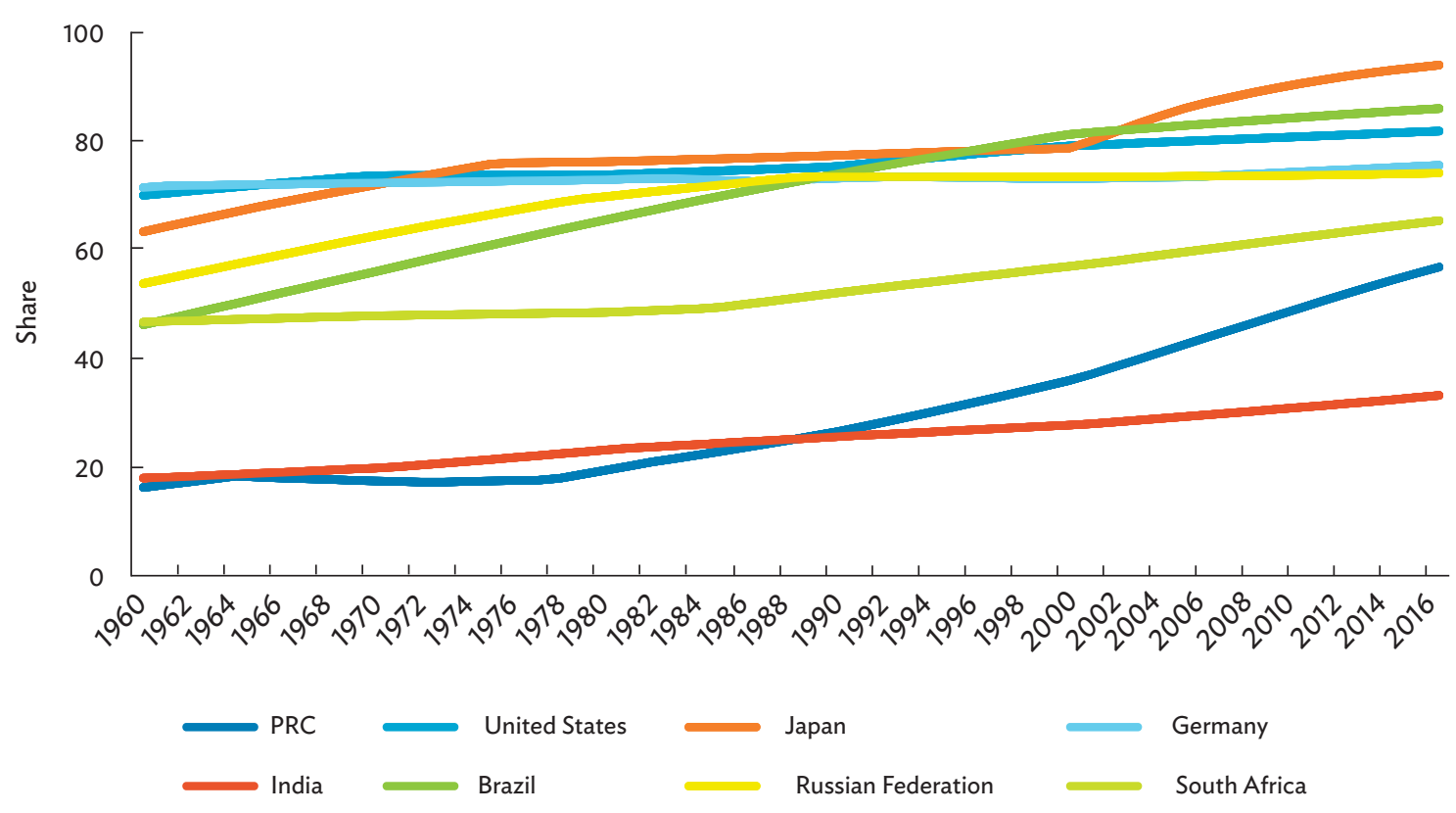

PRC = People's Republic of China .

Source: World Bank, World Development Indicators.

Figure 9: Per Capita Disposable Income of Urban versus Rural Residents, 1978-2016

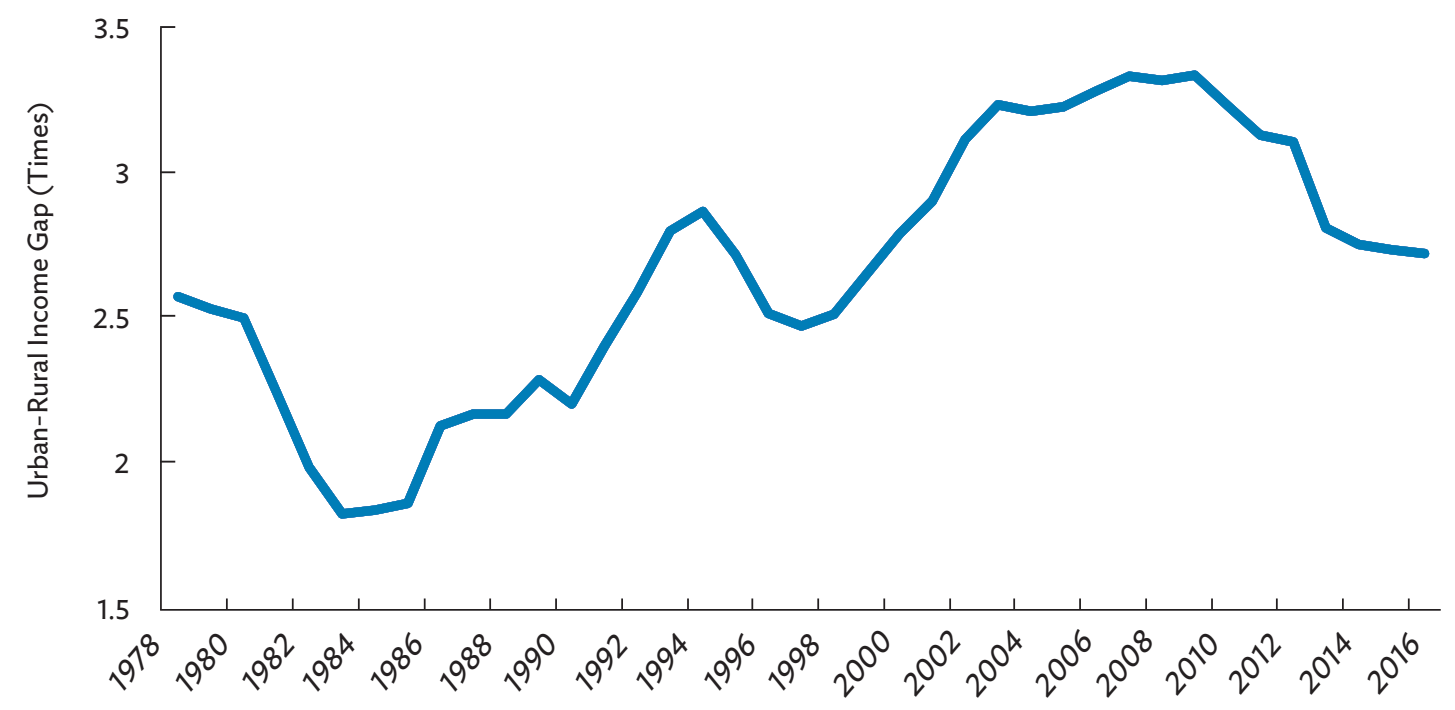

Source: National Bureau of Statistics. 
The PRC's urbanization process is far from over, and many more people from rural areas will move to urban areas during the Fourteenth Five-Year Plan period (2021-2025). Positive changes, including efficiency improvements and human capital accumulation, will happen because of the reallocation of labor, industrial agglomeration, and other factors. However, the urbanization process will also cause serious problems and challenges, among them insufficient public services, resource and environmental constraints, and "urban diseases" because of a rapidly growing urban population. How to balance the various relationships and contradictions caused by this, especially those between farmers and urban residents, and between agriculture and other industries, will be vital for promoting coordinated development.

\section{Regional Structure}

The PRC's population and economic activity show salient regional characteristics because of geography, industrial policies, history and culture, and many other reasons. A particular feature of these regional characteristics is the significant differences between the eastern, central, and western regions in economic and social development and structure. With the population increases and industrial mobility of recent years, the regional distribution is also changing, although gradually. This change first manifested itself by migration from the central and western regions to the east. From 2000 (the year of the fifth national census) to 2016, the percentage of the population in the eastern region increased from $39 \%$ of the total population to $42 \%$. In the same period, the central region's population declined from $33 \%$ to $31 \%$ and the western region from $28 \%$ to $27 \%$. This trend is even more pronounced when measured by the migration to some mega-cities and urban agglomerations.

Figure 10: Gross Domestic Product per Capita in Eastern and Central Regions Compared with the Western Region, 2003-2016

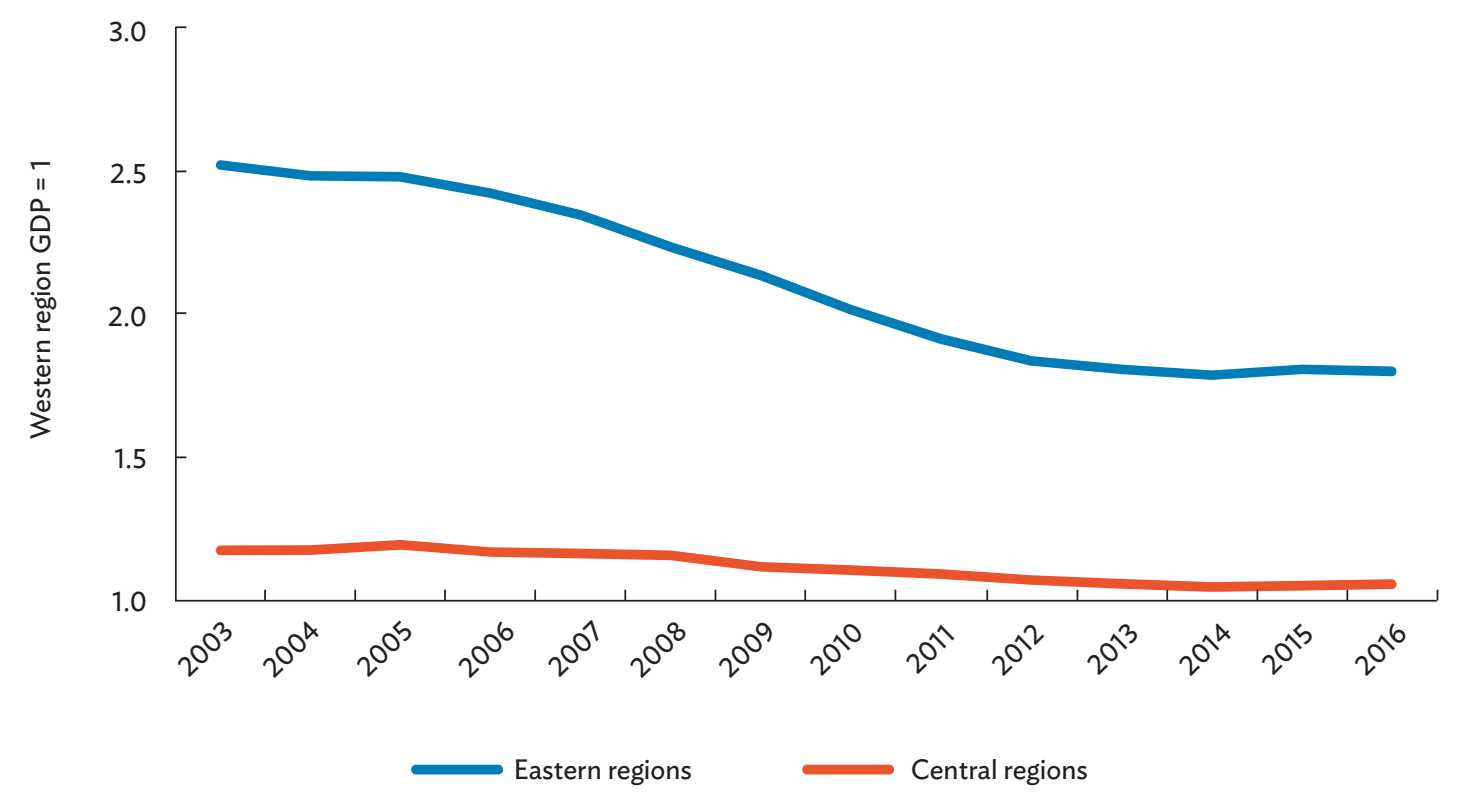

GDP = gross domestic product.

Source: National Bureau of Statistics. 
An increasingly mobile population is also redistributing economic activity. Because of declining investment returns, and sloping development strategies and transfer payments, the proportion of eastern-region GDP to national GDP has declined in recent years, from 60\% in 2003 to 55\% in 2016. In the same period, central-region GDP increased from $23 \%$ to $25 \%$; and in western-region GDP, from $17 \%$ to 20\%. The gap in GDP per capita of the three regions is also narrowing. From 2003 to 2016, the ratio of GDP per capita in the eastern region fell from 2.5 to 1.8 times, and from 1.2 to 1.1 times in the central region, compared with the western region (Figure 10). This largely reflects the narrowing gap in interregional economic efficiency.

Going by the current characteristics of industrial migration and policy direction, such as the poverty reduction strategy and new urbanism, population mobility between regions, spatial reconstruction of economic activity, and even development arising from the "convergence", these trends are expected to continue in the medium term. This will be the factual context when formulating regional development planning and policy frameworks in the medium term. The focus of coordinating this should therefore be on promoting and guiding rational spatial allocation of industries, factors, and demands.

\section{E. Recommendations to Promote Balanced Development}

The key to promoting coordinated development is to resolve the root cause of distortions and imbalances. Coordination is not just government adjusting structural parameters, such as the share of the services sector and the urbanization rate; coordination needs to be gradually achieved by market and price signals, and incentive mechanisms.

In general, the cause of distortions and imbalances is not less government intervention, but more government intervention. To solve this problem is to give full play to the decisive role of the market and the coordinating function of society itself, and not to generate new distortions and imbalances under the pretext of growth catch-up. The following recommendations are offered to promote balanced development.

(i) Coordinated regional development. In promoting coordinated development in Beijing, Tianjin, and Hebei, the government has not let the market mechanism play an active role, especially in the process of population mobility and labor resource allocation. The government has instead made excessive use of administrative means to do this. The Beijing-Tianjin-Hebei economic circle plays a vital role in national-market integration, and its demonstration effect is important. Attention should therefore be paid to coordinating regional and nationwide development goals to avoid fragmented new markets from forming. Economic development in the northeast has been stagnant in recent years, and so a vigorous effort is needed to build a long-term mechanism of economic development for this region. To do this, the market mechanism needs to be further fostered, and the previous development model that relied on external forces and projects abandoned. Reforms to the public governance mechanism are needed to improve the business and investment climate. A greater effort is needed to carry out supply-side structural reforms to deal with the relationship between the traditional driving forces of economic growth and the new ones, and between the state-owned economy and the nonstate-owned economy.

(ii) Coordinated urban-rural development. People-centered urbanization is the principal means to promote the coordinated development of urban and rural areas. A greater emphasis is needed on this. It is noteworthy that some medium- and long-term institutional mechanisms to promote people-centered urbanization still need to be put in place by intensified reforms. With a floating population of 244 million in 2017, 820,000 fewer than in 2016, a trend toward stagnant mobility seems to be emerging. Promoting population mobility is continuing to help raise urban-rural integration. 
The fundamental means to promote the coordinated development of urban and rural areas is to raise the quality of urbanization, especially through scale and agglomeration effects in large- and medium-sized cities, and by promoting the development of surrounding small- and medium-sized cities and towns. Urbanization should be people-oriented. In 2017, the proportion of the urban population (urbanization rate) to the total population was $58.5 \%$, an increase of 1.17 percentage points over 2016. It is necessary, however, to avoid the phenomenon of increasing the urbanization rate through administrativedivision adjustment. Even more important will be accelerating reforms to the household registration system to narrow the gap in the level of social protection between urban and rural residents. For urbanization, it is necessary to respect population mobility, give full play to the decisive role of the market mechanism, and to reduce the inefficient allocation of economic resources caused by administrative intervention.

(iii) Coordinated industrial development. This is an important basis for the coordinated development of the entire economy. The industrial structure should be optimized through far-reaching structural readjustments and supply-side structural reforms. The focus on promoting structural adjustment should be on maintaining the advantages of traditional manufacturing industries, and further promoting the development of producer services and strengthening their supporting function to upgrade the manufacturing industry. Raising productivity is the core of coordinated development for all industries, and it is still necessary to cultivate the endogenous mechanism to promote productivity growth. More emphasis needs to be placed on boosting labor productivity, since the services sector already accounts for more than half of the national output.

(iv) Coordinated real estate development. Growing the real estate industry involves urban and rural development, urbanization paths, labor transfers, and income and wealth inequality. The long-term mechanism of real estate development is therefore directly related to coordination. Attention should be paid to migratory needs. The increasing demand for urban housing, as an important part of well-being, is a reflection of people's migratory needs in the context of urbanization development.

From this point of view, housing demand is mainly concentrated in large cities, thus leading to particularly strong demand and even bubbles. If this is ignored, imposing restrictions or failing to keep up with supply may cause problems. It will also be necessary to moderately increase the floor-to-area ratio, which is too low in the PRC. Human factors on the supply side, including institutional, strategic, and policy ones, may result in an insufficient supply of land and houses. Because of a shortage of land for housing, land needs to be used more efficiently, and lessons can be learned from Hong Kong, China; and Japan. For example, floor-to-area ratios in Hong Kong, China can reach from 9 to 10, but Shenzhen's is roughly below 3 . Urban land needs to be distributed rationally. A question that needs to be addressed is how to distribute limited land between large and small cities. This will involve deviating from the urbanization strategy. In the past, the policy emphasized developing small cities because of unlimited land, whereas big cities strictly restricted the supply of land and often set population ceilings for expansion. But because the vast majority of migrants are moving to big cities, three- and four-tier small cities and towns (not in the majority of the metropolitan group) are suffering population outflow. The main reason for this is that big cities generally provide more jobs than smaller cities. So, at this stage of industrialization and urbanization, it seems reasonable to concentrate on developing big cities, and to increase their supply of land and urban agglomerations, while reducing the supply of land in small cities where there is population outflow. In the spirit of market-oriented reform, developing the real estate market must follow the direction of marketization and let the market play a decisive role in the allocation of resources. 


\section{GREEN DEVELOPMENT}

\section{A. Current Situation and Problems}

Four decades of high-speed industrialization and economic growth has taken a huge toll on resources and the environment, which threaten the sustainability of development. Yet, the economy's structural transformation, and the constraints on resources and environmental challenges, have also provided a new objective basis and the external conditions for a harmonious coexistence between the environment and socioeconomic development. Widespread popular support for green development is providing the impetus for changing the mode of development and promoting the construction of an ecological civilization.

The PRC's economic development is characterized by high carbon emissions, energy consumption, and pollution although the situation has improved in recent years. The international comparisons in Figure 11 show that at the beginning of the reform and opening-up, carbon emissions per unit of GDP were nearly seven times that of the United States and 15 times that of Japan. They were also much higher than those of Brazil, India, and other emerging economies in the same period. Since then, the PRC's carbon emissions have declined steadily, from 4.97 kilograms per dollar in 1978 to 1.23 in 2014 (the latest year for which data are available), a reduction of nearly a quarter. Even so, they are still 3.8 times that of the United States, and close to the levels in India and the Russian Federation.

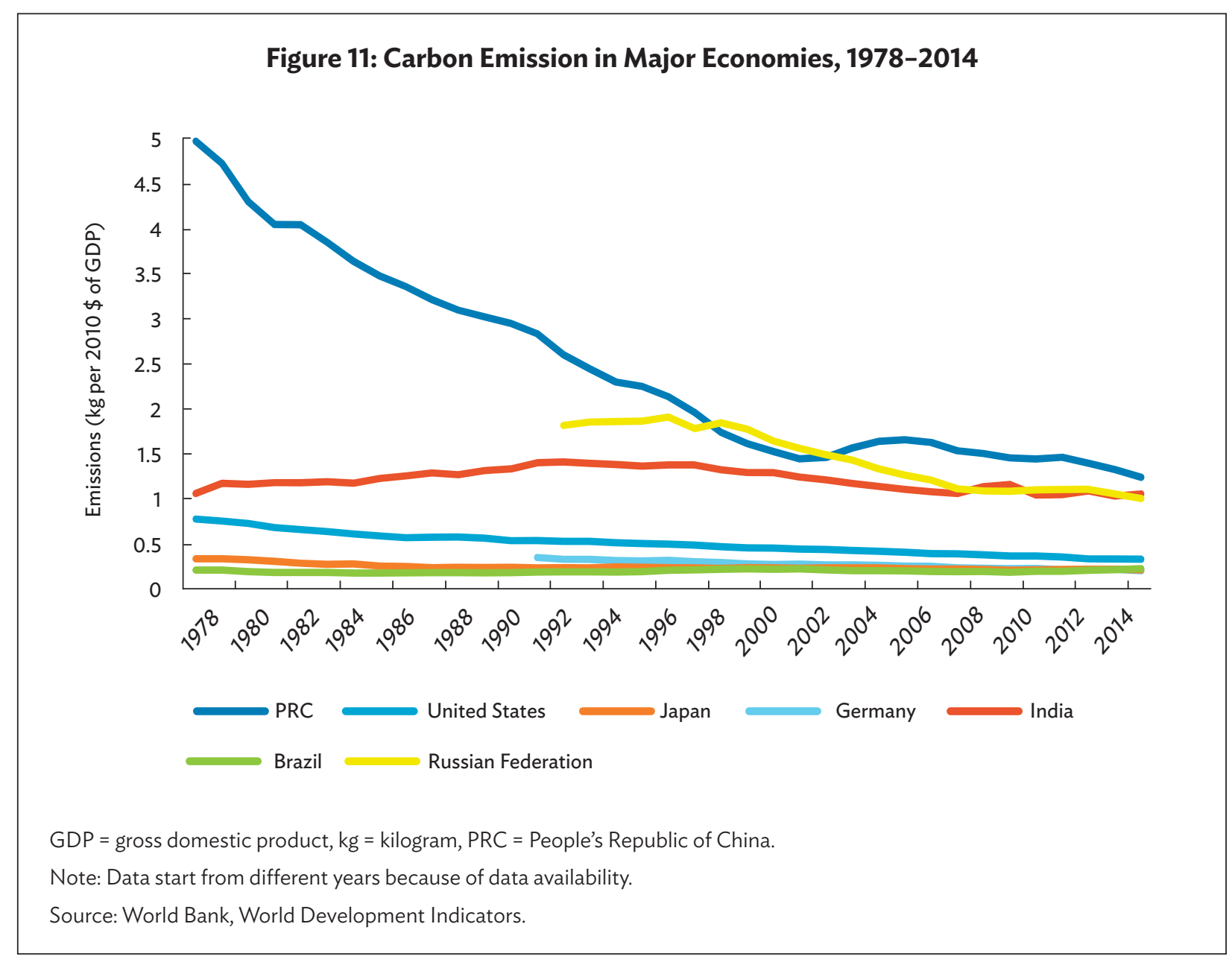


The PRC's energy consumption per unit of GDP is also significantly higher than other major economies. The PRC consumed more than twice as much energy per unit of GDP as the United States in the early 1990s, three times as much as Germany, and four times as much as Japan (Figure 12). After the PRC's energy consumption peaked in the mid-1990s (with a slight increase after 2008), it has been lower than the Russian Federation's in recent years and close to the other countries shown in the figure (only 31\% higher than the United States in 2014).

\section{Figure 12: Fuel Consumption Equivalent per Unit of Gross Domestic Product in Major Economies, 1990-2014 (kgoe)}

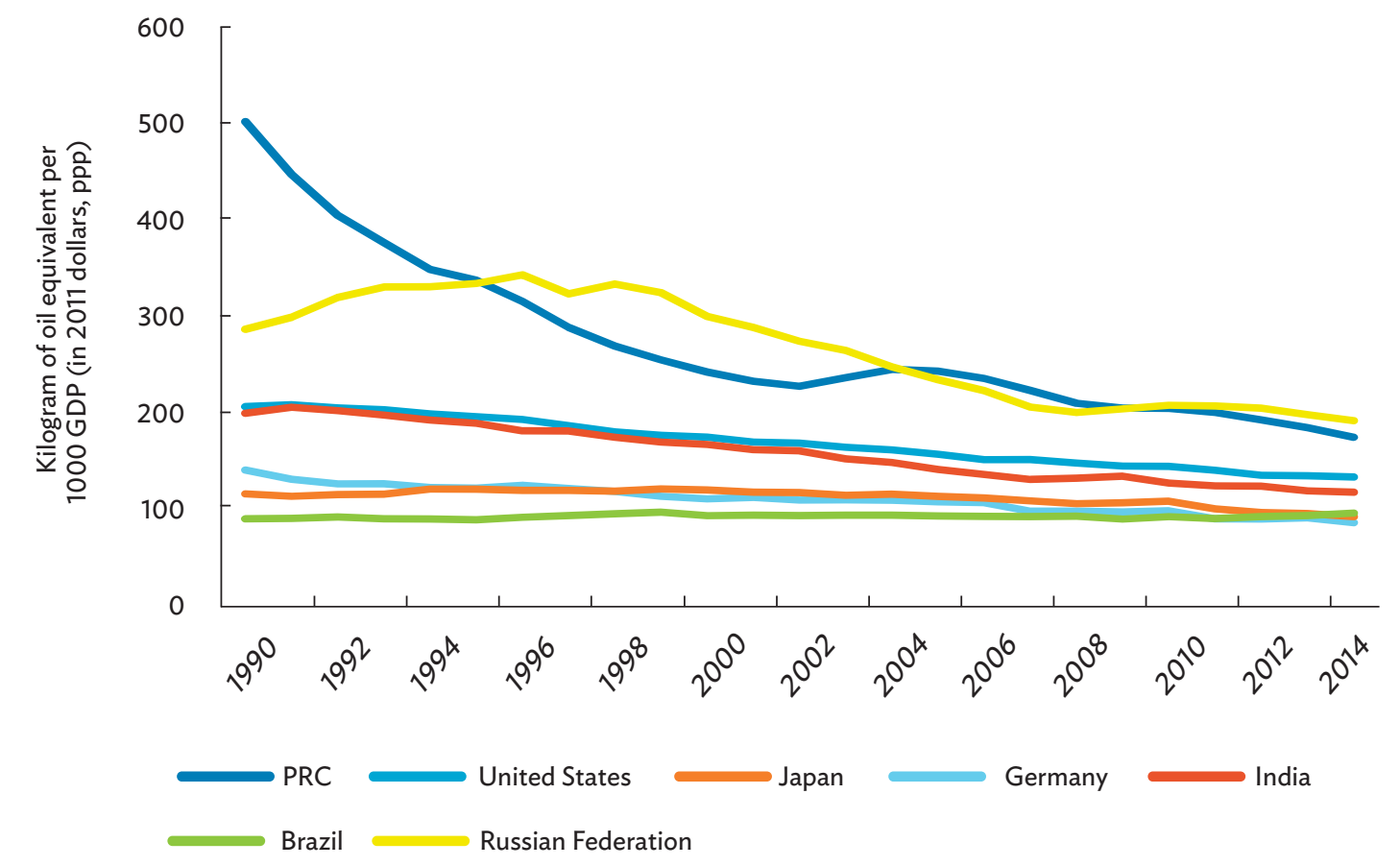

GDP = gross domestic product, kgoe = kilogram of oil equivalent, $\mathrm{PPP}=$ purchasing power parity,

PRC = People's Republic of China.

Source: World Bank, World Development Indicators.

There are also significant differences in the energy mix between the PRC and developed countries (Figure 13). The PRC has long relied heavily on coal, which accounts for $60 \%-70 \%$ of total energy consumption, followed by oil (20\%). The structure of the energy mix is the main cause for high emissions and pollution. On the plus side, the energy mix is moving toward clean energy sources, such as natural gas, hydropower, nuclear, and wind power. The proportion of clean energy sources in the total energy mix rose from less than $10 \%$ in 2000 to $20 \%$ in 2016 . This is still slightly below the world average, and the proportion of clean energy consumption remains low compared to developed countries. In the United States, energy consumption other than oil and coal accounted for 46\% of total energy consumption in 2015 (Figure 14). 
Figure 13: Structure of Energy Consumption in the People's Republic of China, 2000-2016 (\%)

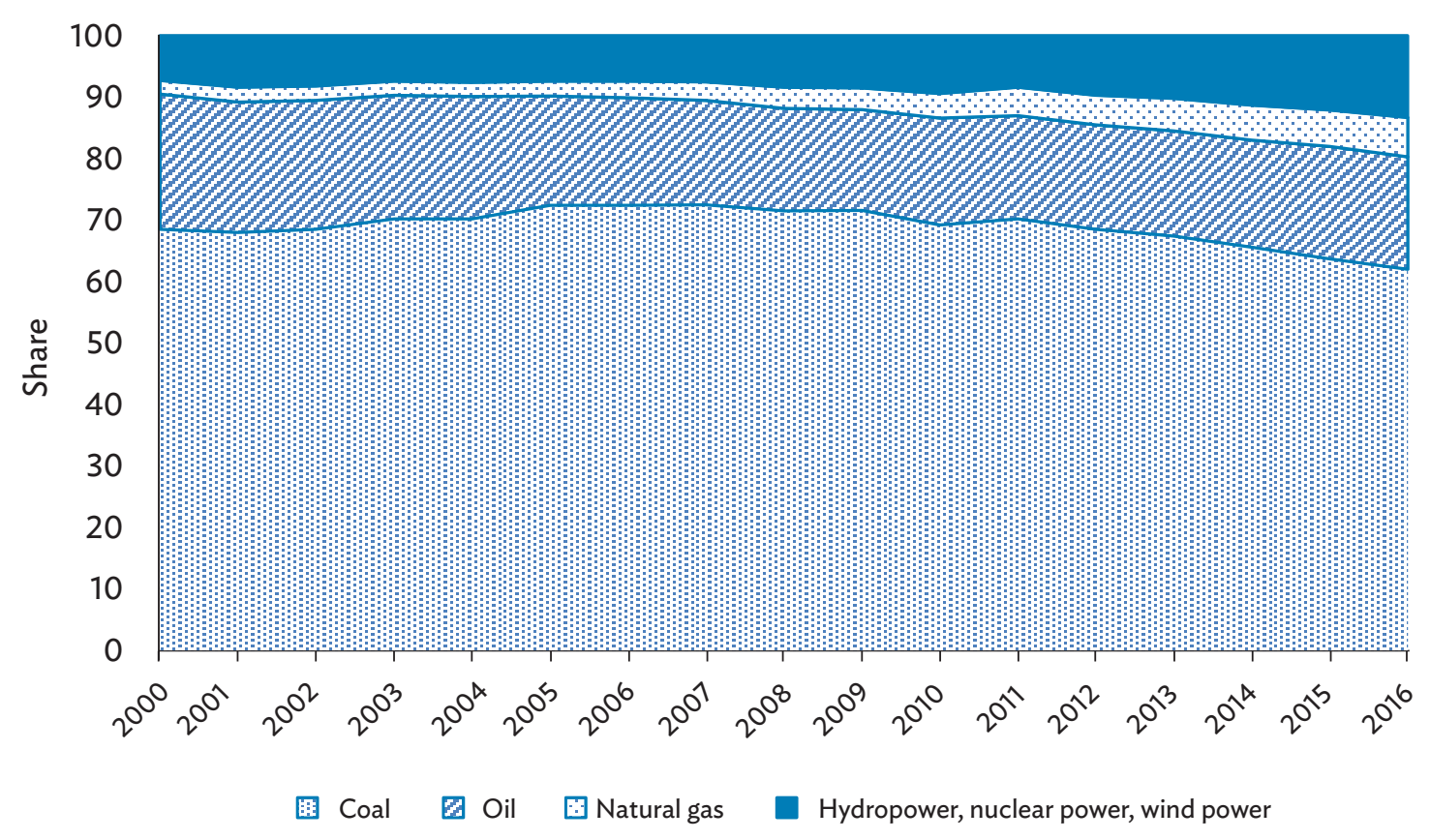

Source: National Bureau of Statistics.

Figure 14: Structure of Energy Consumption in the United States, 2015 (\%)

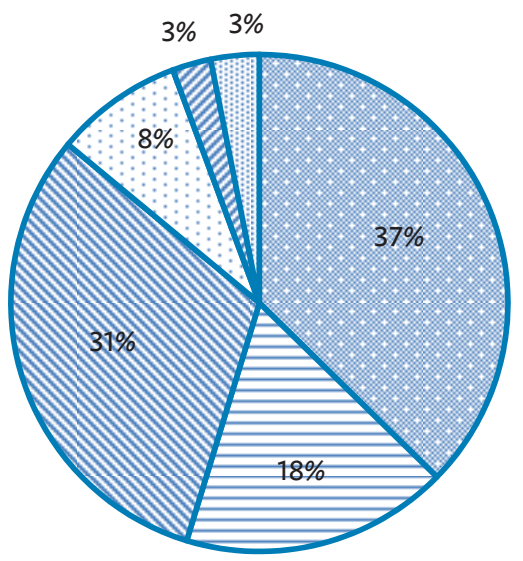

M Oil $\square$ Coal $\mathbf{\Delta}$ Natural gas $\square$ Nuclear power $\mathbf{\square}$ Hydropower $\mathbf{B}$ Other renewables Source: BP (2016). 
The PRC's emissions of industrial domestic wastewater and exhaust pollutants are high because of large and low-end industries, and the development of public infrastructure that is lagging behind the pace of urbanization. Still, emission and pollution levels have been declining in recent years, particularly emissions of sulfur dioxide, a major contributor to air pollution and acid rain. These fell by almost by half from 2010 to 2016 (Table 1).

Table 1: Emissions of Wastewater and Waste Gas Pollutants

(billion tons for wastewater; million tons for others)

\begin{tabular}{lcccc}
\hline Year & Total Wastewater Discharge & Sulfur Dioxide & NOx & Smoke Powder and Dust \\
\hline 2010 & 61.73 & 21.85 & $\ldots$ & $\ldots$ \\
\hline 2011 & 65.92 & 22.18 & 24.04 & 12.79 \\
\hline 2012 & 68.48 & 21.18 & 23.38 & 12.36 \\
\hline 2013 & 69.54 & 20.44 & 22.27 & 12.78 \\
\hline 2014 & 71.62 & 19.74 & 20.78 & 17.41 \\
\hline 2015 & 73.53 & 18.59 & 18.51 & 15.38 \\
\hline 2016 & 71.11 & 11.03 & 13.94 & 10.11 \\
\hline
\end{tabular}

$\ldots=$ not available, $\mathrm{NOx}=$ nitrogen oxide and nitrogen dioxide.

Source: National Bureau of Statistics.

\section{B. Prospects for Green Development}

A key question for examining the prospects for green development in the PRC is whether an "environmental" Kuznets curve will appear. The original economic concept of a Kuznets curve was put forward by American economist Simon Kuznets in the 1950s. This hypothesizes that the inequality of income distribution first increases and then decreases as an economy develops, with this trend forming an inverted U-shaped curve. Building on this logic, Grossman and Kruger (1995) put forward an environmental Kuznets curve. Here, pollution rises first and then declines as an economy develops.

The PRC's carbon emissions per unit of GDP and energy consumption are on a downward trend. Figure 15 shows the growth of emissions has slowed markedly since about 2012 after they expanded rapidly in the early 2000 s amid strong economic growth. Although there is no "inflection point" of emissions up to 2014, the end of the period covered in the figure, a sustained and stable reduction in total emissions may occur in the near future. In other words, the inflection point of the environmental Kuznets curve is crossed because of factors such as a slowdown in economic growth, changes in industrial structure, and a reduction in unit emissions. Scholars are looking at scenarios related to this. Lin and Li (2015) point out that the PRC's carbon emissions could peak during 2023-2028 because of changes in coal consumption and improved environmental governance. On the basis of available information, the PRC looks set to comfortably achieve its nationally determined contribution to the Paris climate change agreement by peaking of carbon emissions by 2030 .

The PRC's total energy consumption appears to have undergone a similar change, growing rapidly during the first decade of this century and showing signs of slowing in recent years (Figure 16). But unlike carbon emissions, energy consumption per capita is likely to continue its upward trend because of lifestyle changes. Hao, Ling'ou, and Rui (2018) estimate the PRC's total energy consumption will rise slightly, at least in 2022. On the basis of the experience of developed countries, the scenario analysis in Shen et al. (2015) shows there are many paths to the future change of energy consumption in the PRC, which could possibly take place in 2035-2045 or in 2050. In short, the PRC's overall and per capita energy consumption are likely to continue growing in the medium term and beyond, and this will be one of the major challenges for advancing green development. 


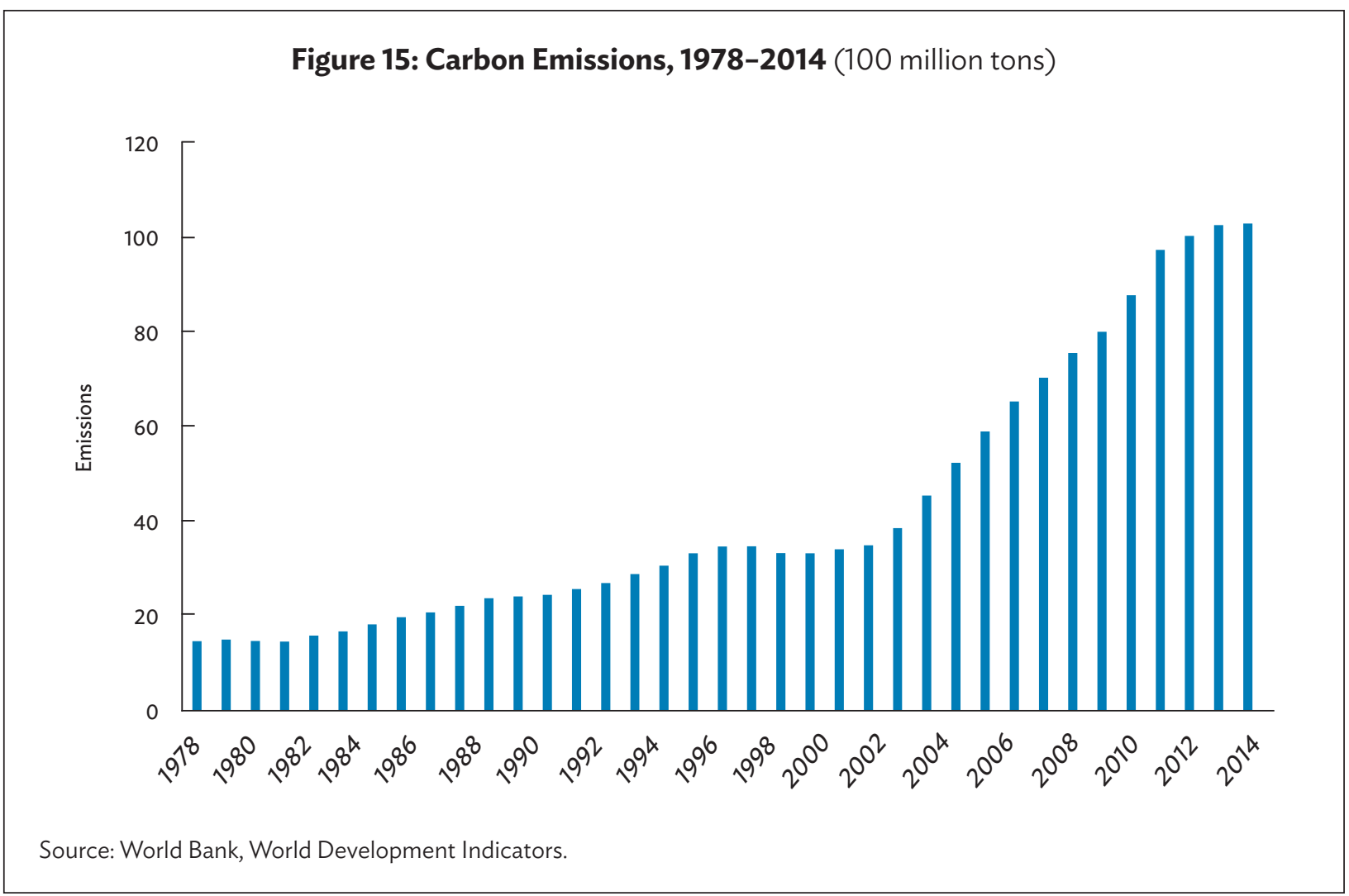

Figure 16: Oil Equivalent of Energy Consumption in the People's Republic of China (100 million tons)

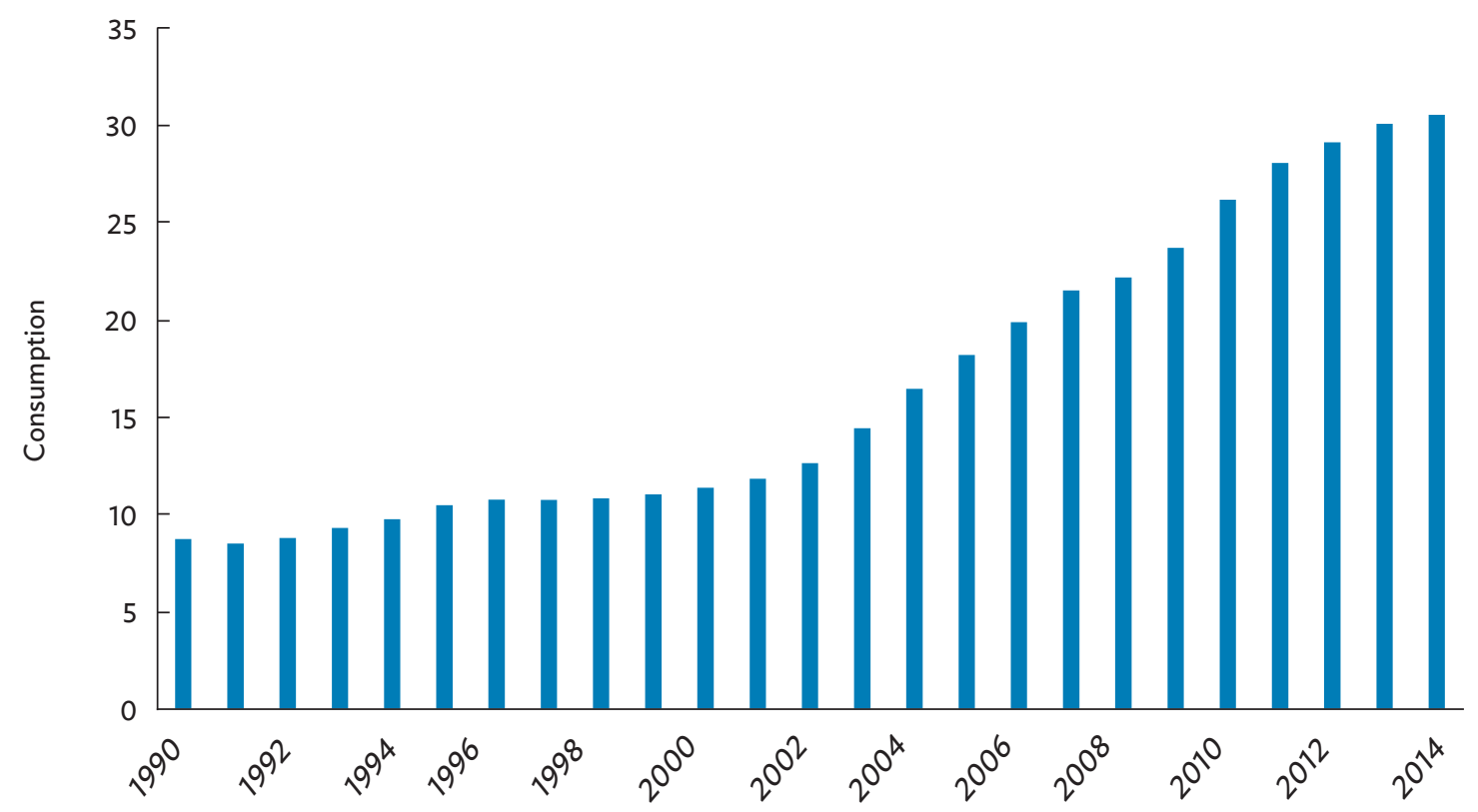




\section{Recommendations to Advance Green Development}

Historically, leading and later-developing countries have been faced with a difficult problem: how to harmonize development and environmental issues. Both have long been regarded as antagonistic, as seen in the zero-growth approach proposed by the Club of Rome to preserve ecological balance. Guided by "development before governance" and "development with governance," the PRC heavily sacrificed the environment in favor of fast economic growth. Green growth unifies economic development and environmental care, especially the protection of productive forces and the development of productive forces. This is reflected in the following recommendations to advance green development:

(i) Promote all aspects of green development. The focus of this should be economic and energy restructuring. A greater effort is needed to optimize the spatial distribution of land development; adjust the distribution of industries in regional watersheds; foster and strengthen clean, energy-saving, and environmental protection industries; promote comprehensive conservation and the recycling of resources; achieve circular links between the production and the living system; advocate a moderate, green, and low-carbon lifestyle; and oppose extravagance, waste, and unreasonable consumption.

(ii) Solve the big ecological and environmental problems. It is important to make the marked improvement in air quality a rigid requirement, and to eliminate heavy air pollution. Action plans for water pollution prevention and control should be thoroughly implemented to ensure safe drinking water. The action plan for preventing and controlling soil pollution should also be fully implemented, especially in key areas, industries, and pollutants, and to strengthen soil-pollution control and remediation.

(iii) Improve environmental governance. Setting up a market mechanism for ecological and environmental governance needs to be accelerated. The first step is to establish a cross-regional ecological compensation mechanism as soon as possible to promote the coordination of a regional and watershed ecological environment. Establishing water rights, emissions trading, and other market mechanisms should follow, using public-private partnerships and third-party environmental governance. The goals for achieving an overall improvement in the ecological environment of the Thirteenth Five-Year Plan have made remarkable progress. For the second half of the plan period, environmental governance should be stringently applied. Laws, regulations, and a standards system need to be set for an effective market mechanism for ecological and environmental governance and to strengthen the system for supervising pollution discharges in the corporate sector. A social supervision mechanism for ecological environment is needed to secure green development. To this end, a local environmental protection tax was introduced in 2018 that is integrated into local finance. To make this tax effective, a government environmental protection fund could be set up to use revenue from this tax as the main source of funds for ecological and environmental governance. The central government's environmental protection supervision has played an important role in realizing the 2017 phased governance goals, which should be further institutionalized and standardized. 


\section{OPEN DEVELOPMENT}

\section{A. Current Situation and Problems}

The trade disputes between the PRC and United States are escalating, and counter-globalization is emerging. Under these complex and changeable conditions, the PRC will likely continue to promote a new pattern of comprehensive openness. To advance this, efforts need to be made in the following areas:

(i) Trade dependence. The PRC's trade dependence-measured by the share of total exports and imports to GDP-has been declining since about 2005, although the absolute level is still high (Figure 17). The rising trade tensions between the PRC and the United States, and the growth in domestic demand, indicate that the country's dependence on foreign trade may decline further, and that imports and exports will tend to balance. A point to note is that since the global financial crisis, the United States' trade dependence has become higher than its precrisis level (Figure 18).

(ii) Capital flows. The PRC ranked second in the world in 2018 for attracting foreign direct investment (FDI) of $\$ 139.0$ billion, up $2.0 \%$ on the previous year. In the same period, the United States attracted FDI of $\$ 251.8$ billion, down $8.6 \%$. For capital outflows, the PRC's outward investment in 2017 was $\$ 125.0$ billion, down 36.2\% from 2016, ranking third in the world. The United States was first, with outward investment of $\$ 342.0$ billion, followed by Japan ( $\$ 160.0$ billion).

Figure 17: Trade Dependence of the People's Republic of China, 2000-2016 (\%)

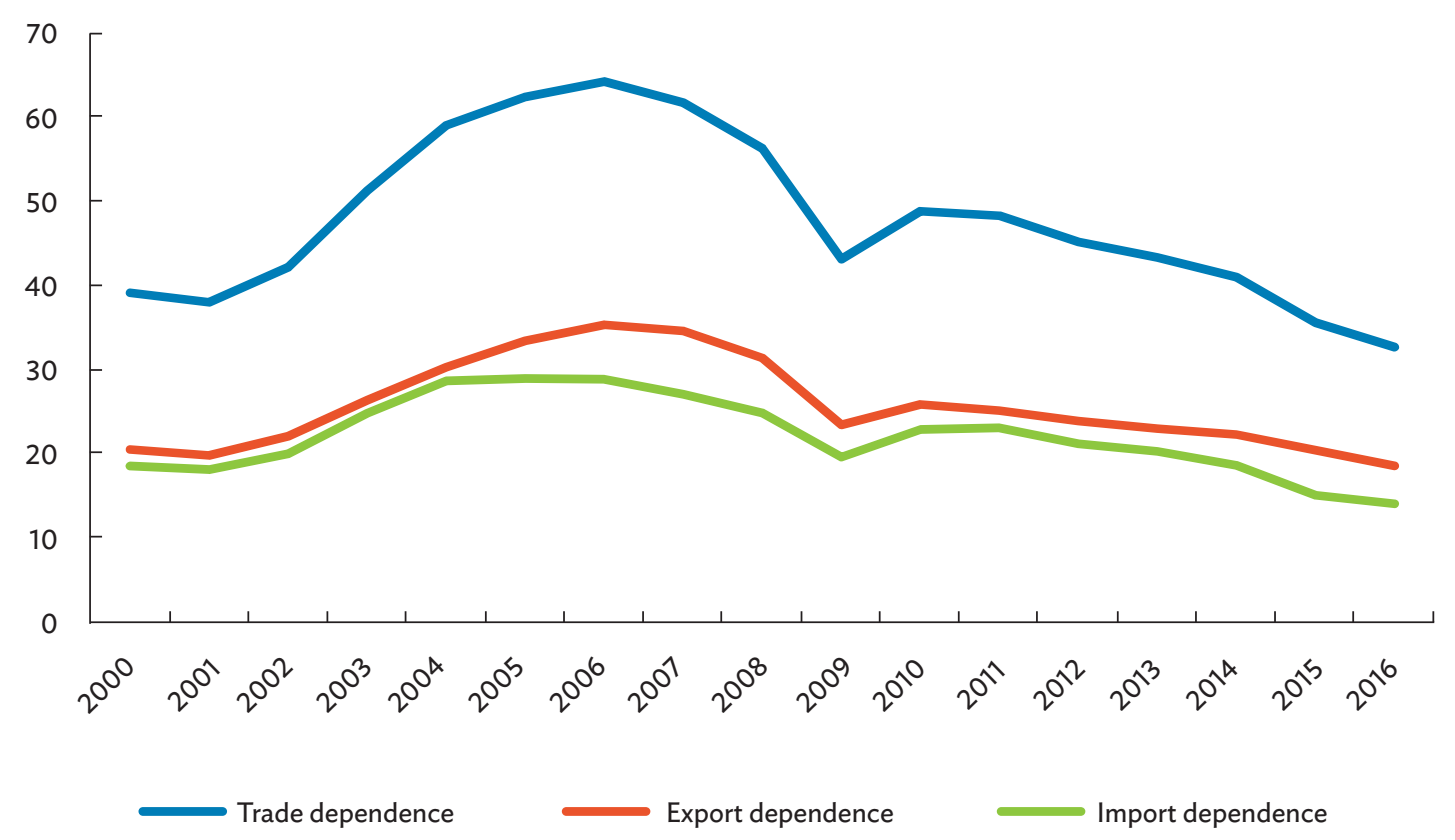

PRC = People's Republic of China.

Source: National Bureau of Statistics. 
Figure 18: Trade Dependence of the United States, 2005-2017 (\%)

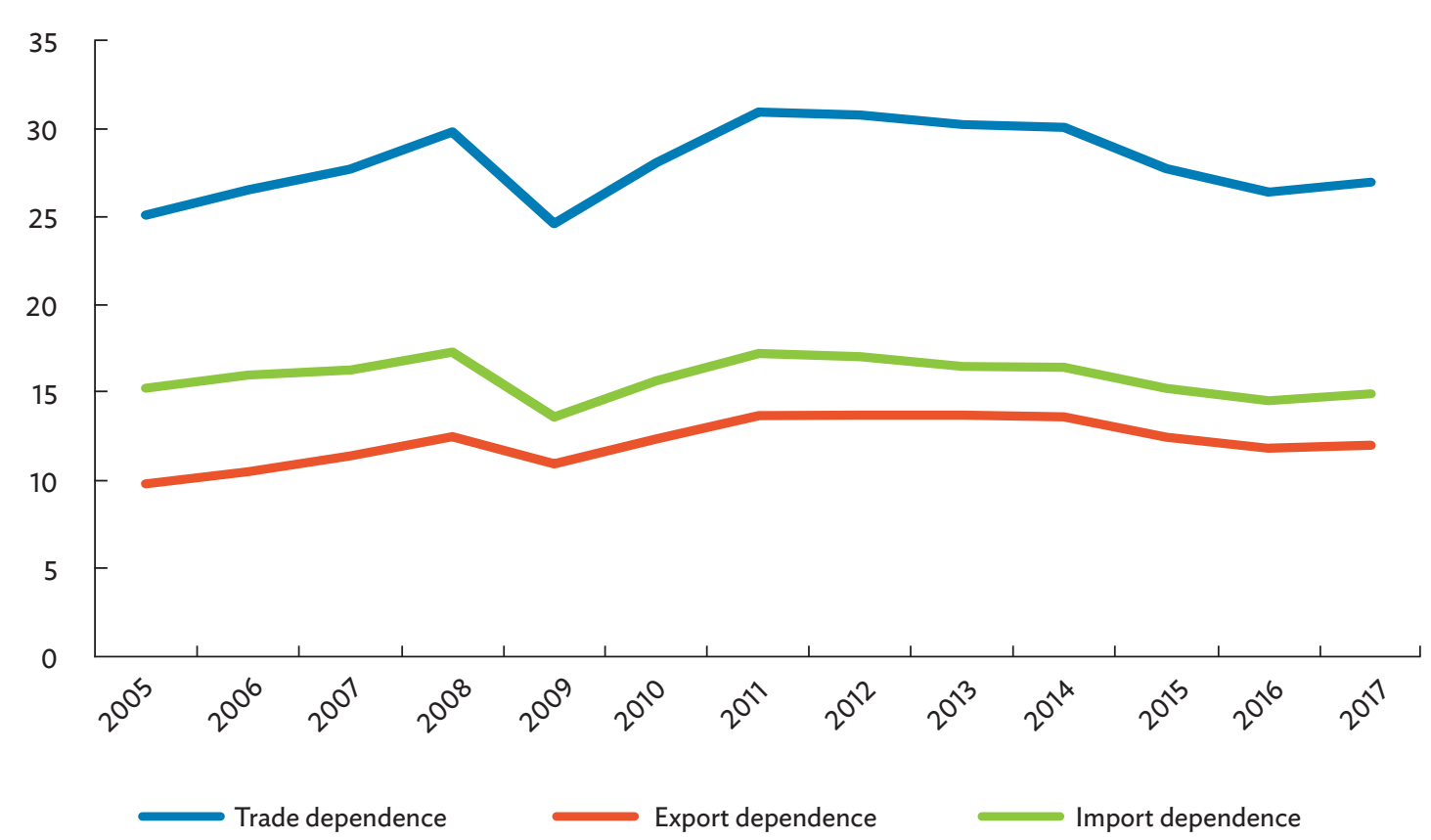

Source: United Nations Conference on Trade and Development.

Figure 19: Inward and Outward Foreign Direct Investment, 1995-2017 (\$ billion)

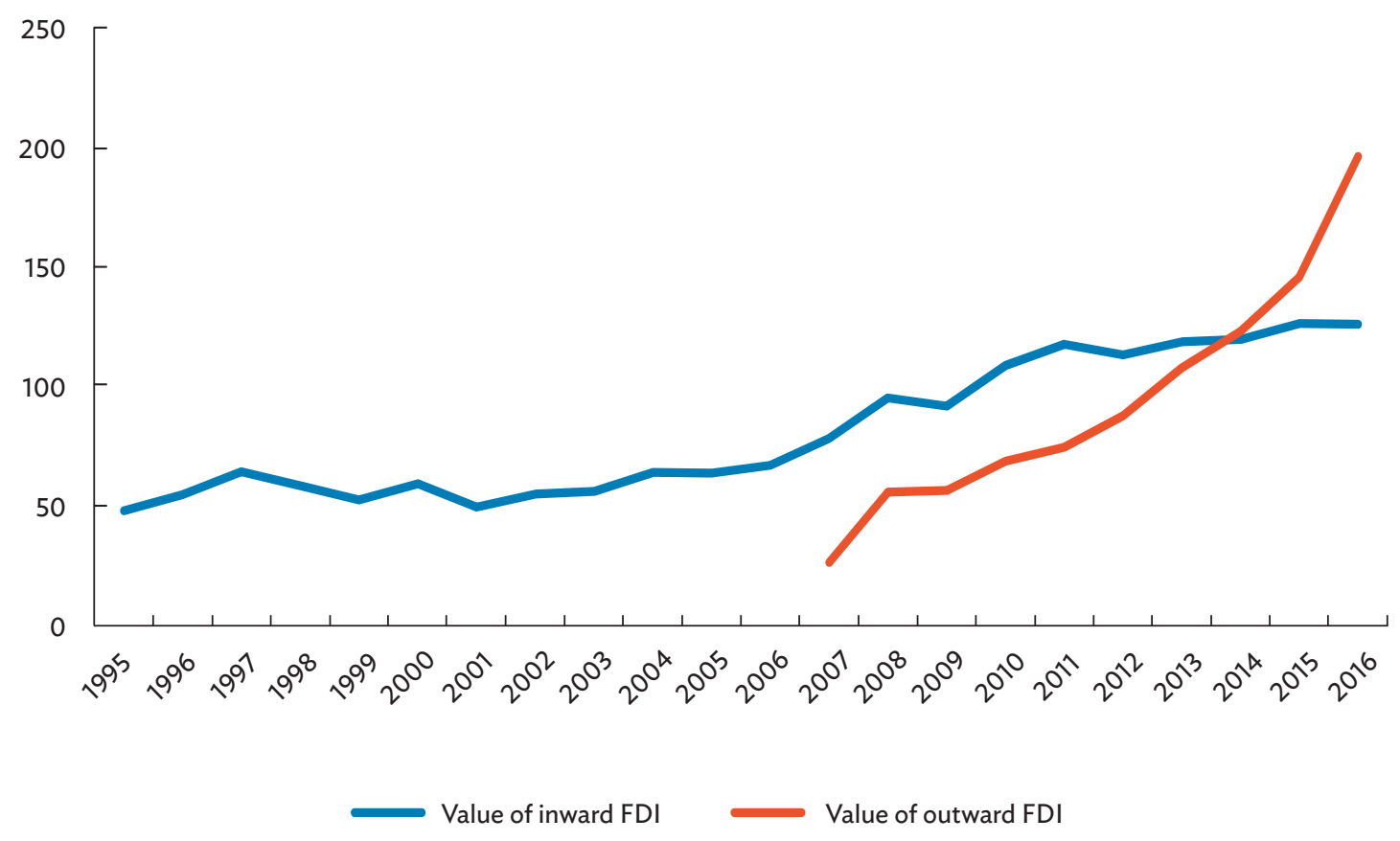

FDI = foreign direct investment.

Note: Breaks in chart line due to data not being available.

Source: National Bureau of Statistics. 
Going by international experience, as GDP per capita increases, the proportion of FDI and outward direct investment in a country's GDP rises (Figure 19). In 2014, the PRC's outward direct investment exceeded FDI. As the country opens further to the rest of the world, its cross-border capital flows will continue to increase. In the medium and long term, FDI and outward direct investment have strong potential for growth, both in absolute terms and as a proportion of GDP.

\section{B. Structure, Quality, and Benefits of Capital Inflows}

From 2007 to 2016, the PRC's industrial structure for attracting FDI was characterized by a significant decline in the proportion of FDI in manufacturing and real estate, and by an increase in other industries. This indicates that the distribution of FDI is more balanced and that the structure is improving (Figure 20).

Figure 20: Foreign Direct Investment by Sector, 2007 versus 2016 (\%)

2007

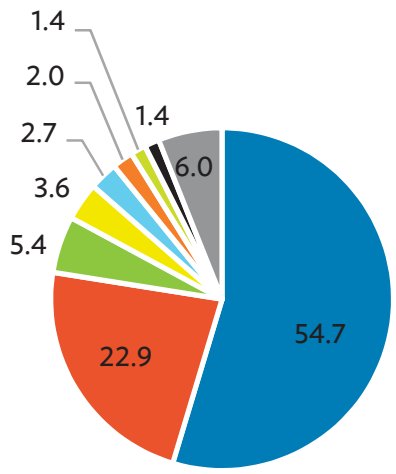

\footnotetext{
- Manufacturing - Real estate - Leasing and business services

- Transport, storage, and post

- Production and supply of electricity, - Hotels and catering services gas, and water
}

- Others
2016

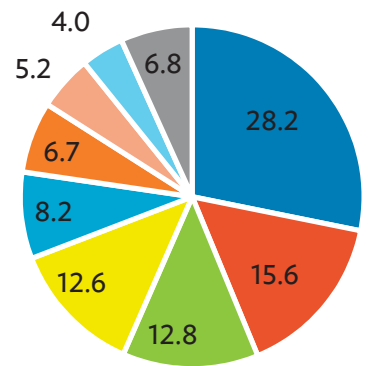
Wholesale and retail trades
- Information transmission, computer service, and software
॥ Scientific research, technical service, and geologic prospecting

Source: National Bureau of Statistics.

The quality and efficiency of foreign capital are mainly measured in terms of the level of economic development and industrial upgrading, and the efficiency improvement of the host country. As the PRC enters a new era of economic development, more attention should be paid to attracting foreign investment with high-tech content and production efficiencies to advance industrial upgrading and efficiency improvement. 


\section{Deficit and Openness of the Services Trade}

The Thirteenth Five-Year Plan states that the proportion of the PRC's services trade in foreign trade should reach $16 \%$ by 2020 ; it reached $14.5 \%$ in 2017 . The experience in developing countries shows that the share of services will continue growing - and it is likely that the PRC's service trade in foreign trade will increase further.

Both imports and exports of the PRC's services trade have been rising since the early 2000s (Figure 21). In 2017, services imports totaled $\$ 464.1$ billion and exports $\$ 226.3$ billion, a deficit of $\$ 237.7$ billion. This was mainly because of a deficit in tourism trade (Figure 22). In 2017, tourism imports totaled $\$ 254.8$ billion and exports $\$ 38.8$ billion, a deficit of $\$ 216.0$ billion, accounting for $90.8 \%$ of the PRC's overall trade deficit in services. Against this backdrop, the focus of efforts to reduce the trade deficit in services should be to promote more tourism. Increasing the use of the PRC's rich tourism resources and attracting more foreign tourists will play a significant role in balancing the trade in services, and advance the opening up of the country.

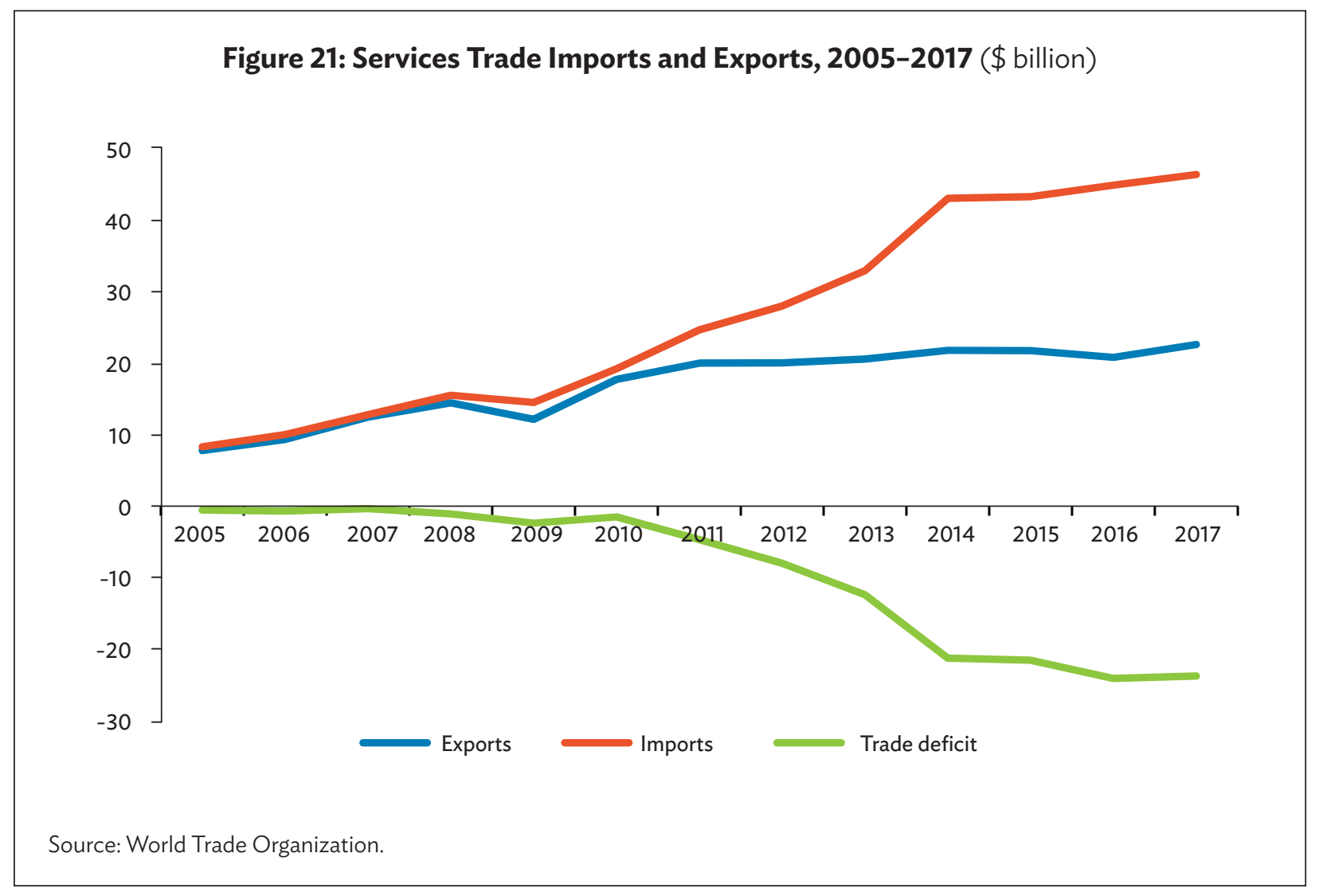


Figure 22: Tourism Trade, 2005-2017 (\$ billion)

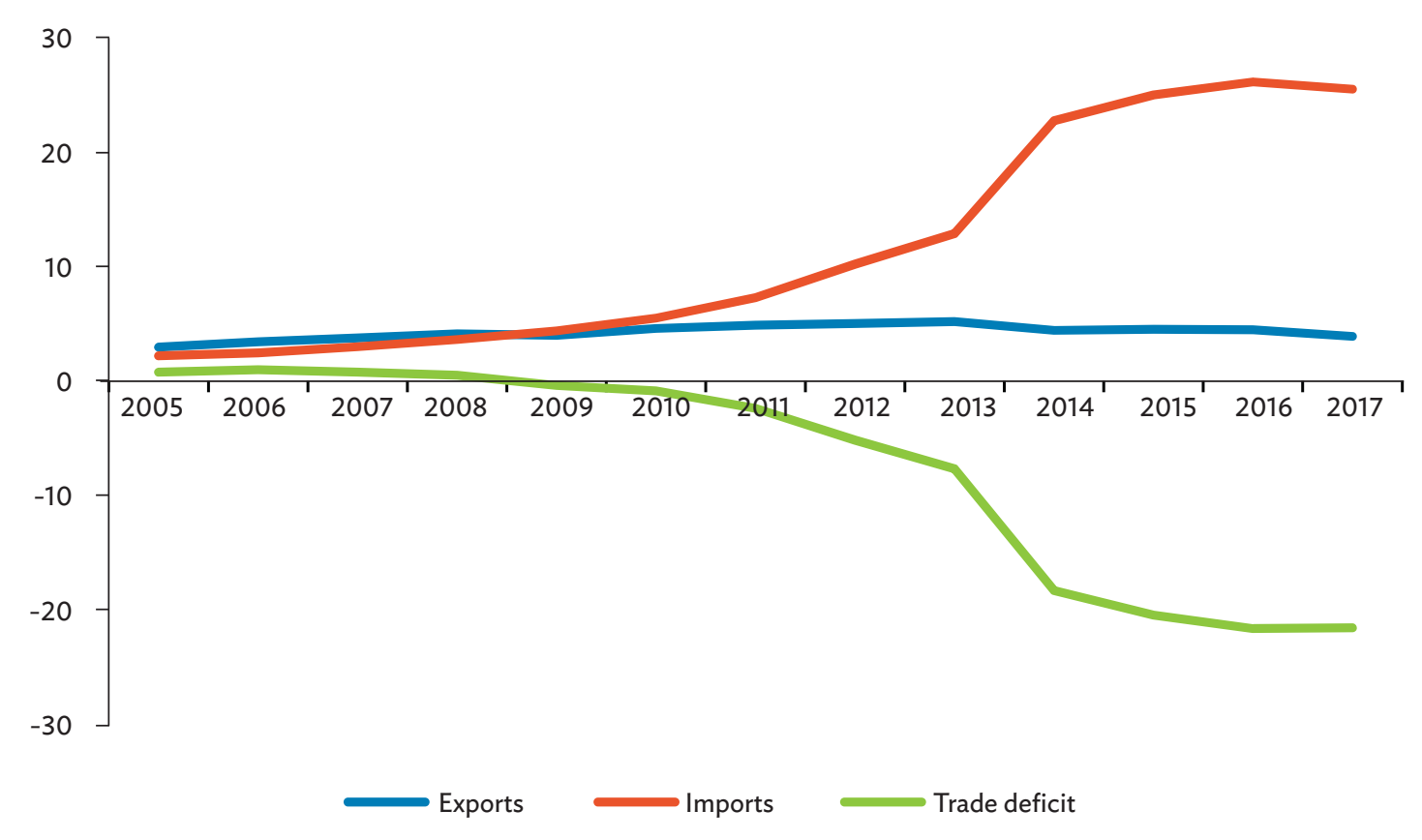

Source: World Trade Organization.

\section{Recommendations for Further Opening Up}

Problems facing open development in the PRC include a backlash to globalization, especially the ongoing trade dispute with the United States; the new alliance formed by Europe, Japan, and the United States to set new trade rules; the PRC's export and FDI development that requires paying more attention to imports and outward FDI; and regional cooperation and integration, which requires a new pattern of opening up.

The new era of economic development will bring new requirements for open development. The focus on capital flows in the past was on inward FDI, but now outward FDI is gaining importance. For commodity trade, instead of an export-oriented strategy, the emphasis nowadays is to balance commodity imports and exports. For trade in services, the PRC has a huge trade gap with developed countries and a longstanding deficit. This situation, however, is expected to be alleviated. The PRC needs to change its current policy orientation on capital and current projects. In particular, the "reciprocal" policy proposed in the trade dispute between the PRC and the United States needs to be considered in the design of open development policies. Both countries need to seek reciprocity in the protection of trade, investment, and intellectual property. Although it may not be realistic to achieve complete reciprocity because of the development gap between them, a policy arrangement should not make inequity or injustice the pretext for conflict. Strengthening trade compliance and reciprocal trade arrangements would reflect an attitude of openness - and this will be a requirement for increasing the PRC's competitiveness.

The following recommendations are offered for advancing open development. 


\section{Improve the Foreign Investment Environment}

To develop a high-quality open economy, a conducive institutional environment needs to be created to facilitate investments and promote trade liberalization and fair competition. In this environment, expectations need to be stabilized. It is important to strengthen the interface with international economic and trade rules, enhance transparency, strengthen the protection of property rights, adhere to the rule of law, and encourage competition and oppose monopolies. The opening up of pilot free-trade zones to foreign firms and the reform of relevant systems need to be accelerated. The construction of free-trade ports needs to be promoted. The list of exclusions for foreign investment access needs to be revised to create equal opportunities in business.

\section{Attract More Foreign Investment and Expand Imports}

This will require paying more attention to the structure, quality, and efficiency of attracting foreign investment and expanding imports. Increasing foreign investment in high-tech manufacturing and services could bring structural benefits. A greater effort should be made on the type of imports that will advance high-quality development in an open economy. Actively expanding imports is not only a shortterm option for achieving a trade balance but also a means to meet people's expectations for a better life. The China International Import Expo in Shanghai is a clear sign of the PRC's continued drive to open its economy.

\section{Progressively Introduce Zero Tariffs for Manufacturing}

Amid the trade dispute between the PRC and the United States, developed economies (including Europe, Japan, and the United States) have strengthened trade integration, and even introduced zero tariff programs. This puts pressure on the PRC's participation in the international division of labor. To counter this, the PRC should gradually introduce zero tariffs for manufacturing.

Data from the Ministry of Commerce (as of the end of 2017) show the PRC gets zero tariffs on more than 8,000 imported products. The PRC has signed 16 free trade agreements with 24 countries and regions, and the final tariff items of free-trade partners account for more than $90 \%$ of total trade products. The PRC has also implemented 15 free trade agreements with 23 countries and regions, covering more than 8,000 kinds of zero-tariff import products. On industrial products, for example, import tariffs on refrigerators, rice cookers, and cosmetics from the Republic of Korea have been cut by $40 \%$, and will be reduced to zero in a few years. The zero-tariff products under the PRC's free trade agreements with other countries also include many intermediate products and raw materials needed for manufacturing domestic consumer goods.

Because tariffs on goods manufactured in the PRC are already low, the impact of zero-tariff arrangements will be very limited. The World Bank's World Development Indicators show that real tariffs on manufactured products of the PRC have declined steadily since the 1990s, falling from 36\% in 1991 to 13\% in 2001. This trend has continued since the PRC's entry into the World Trade Organization (WTO), with tariffs falling below 5\% by 2016. By horizontal comparison, the PRC's tax rate (4.3\%) is still higher than that of developed countries. The rates in Germany, Japan, and the United States are all below $2 \%$. The PRC's tax rate is lower than that of other developing countries, including Brazil (9.7\%) and India (6.3\%), and it is close to the Russian Federation (3.4\%). This shows the PRC is not deliberately pursuing a foreign trade surplus through tariff barriers, especially in manufacturing (Figure 23). 
Figure 23: Effective Tax Rates on Manufactured Products in Major Economies, 1998-2016(\%)

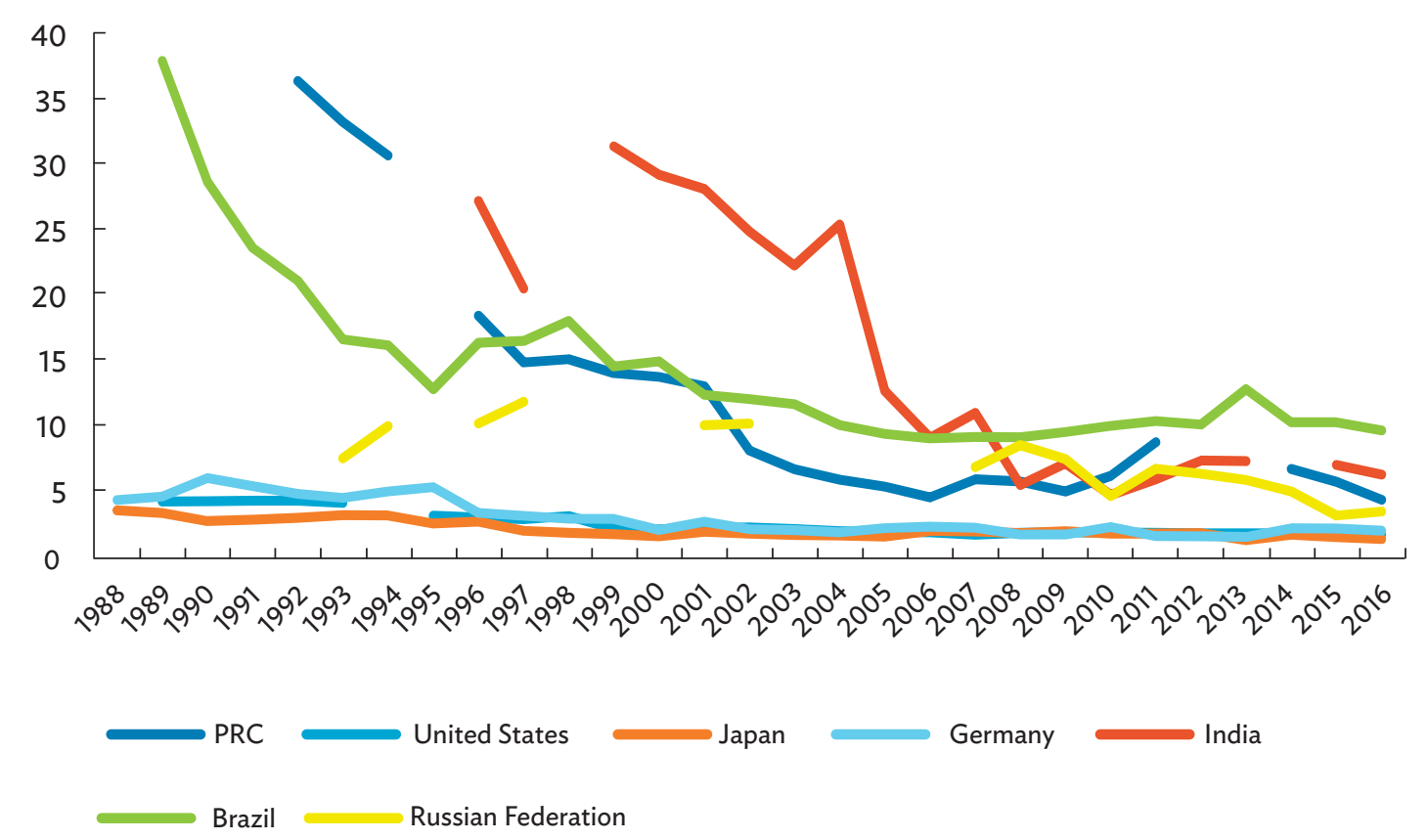

PRC = People's Republic of China.

Note: Breaks in chart line due to data not being available.

Source: World Bank, World Development Indicators.

Zero tariffs on manufacturing have little impact on other domestic industries, especially agriculture. Because the PRC's manufacturing tariffs are already low, a further reduction of tariffs or even zero tariffs will have very limited negative effects on local manufacturing and tariff revenue. To a certain extent, zero tariffs on manufactured products should encourage domestic industries to foster new comparative advantages through scientific and technological innovation and other means, especially by increasing the added value of products. Imports of foreign manufactured goods with low tariffs will encourage domestic consumption, human capital accumulation, and even scientific and technological innovation, thereby contributing to the long-term transformation to high-quality development.

\section{Open up the Services Sector}

The trade in services is a potential growth sector in the global trading system. During 2013-2018, the proportion of global service exports in total exports has increased by an average of nearly 1 percentage point a year, and trade in services will likely continue to grow in importance in global trade. The PRC should proactively participate in this market trend. Domestic market demand for financial, education, medical, and other services is growing rapidly, but the quality and efficiency of domestic supply cannot keep up. Although the services industry's share of GDP is more than half, the overall level of this industry's development is still low. Traditional labor-intensive services are a prominent feature of the industry, and the proportion of high-end producer services remains low. Upgrading the services industry as part of the opening-up process could have a significant effect on promoting supply-side reforms to the industry and improve the quality of life. 
In the financial services sector, market access should be greatly relaxed. For instance, restrictions have been lifted on the proportion of foreign shareholdings in banks and financial asset management companies, and foreign banks can set up branches and subsidiary banks in the PRC on equal terms with domestic banks. Limits on foreign shareholdings in securities, fund management, futures, and life insurance companies has been lowered to $51 \%$, and there is no limit after 3 years of business. It is no longer required that at least one of the domestic shareholders of a joint venture securities company is a securities company. Stock market connectivity between the mainland and Hong Kong, China has been further improved. Foreign capital into the banking and financial sectors, such as trust, financial leasing, automobile finance, money brokerage, and consumer finance, is being encouraged. No ceiling has been imposed on the proportion of foreign shareholdings in newly established financial asset investment companies and wealth management companies initiated by commercial banks. No separate restrictions are to be imposed on the scope of the businesses of joint venture securities companies that have foreign partners; these will have equal treatment with local companies.

\section{Strengthen Trade Policy Compliance}

Compliance is a continuing obligation and should not only cover existing issues but also incremental ones. While WTO negotiations are expected to produce new rules, the PRC's trade policies are still being shaped and new policy documents need to comply with the WTO. The PRC is urged to be transparent in its trade dealings; this will require the regular notification of its trade-related policies, especially subsidy policies. The PRC should also abide by the principle of most-favored-nation treatment. It cannot, for example, grant the United Kingdom preferential treatment without giving other WTO members the same rights, nor can it impose trade restrictions solely on Japan or the United States without doing the same to other WTO members. For goods and services trade, all WTO members must be treated equally - that is, the same as PRC firms - on trade-related intellectual property rights.

For trade-related investment measures, foreign investors should not be restricted by local content requirements, foreign exchange controls, domestic sales, and transfers of intellectual property rights. The PRC must comply with the relevant disciplines for subsidies.1 The government should also fulfill other specific trade commitments. It has, for example, promised to limit nontariff measures, such as export controls, with the ultimate goal of phasing them out. The protection of resources, such as rare earths, should be strengthened in the production sector rather than in the export sector.

\section{SHARED DEVELOPMENT}

\section{A. Current Situation and Problems}

Shared development is not only the original intention of development but also an important guarantee for sustainable prosperity. The essence of shared development is adhering to the concept of peoplecentered development that reflects the requirements of gradually realizing common prosperity. In

\footnotetext{
There are four elements that constitute subsidies: economic actors, (i.e., the government or public institutions); the form of support (i.e., provision of financial support); transmission of interests; and specificity (i.e., for a specific industry, region, or enterprise). Subsidies can be divided into prohibited and actionable subsidies. Prohibited subsidies include export subsidies and import-substitution subsidies. Subsidies other than prohibited subsidies are actionable, and if the actions of other WTO members cause harm to countries' industries, these countries may take countervailing measures or bring the subsidy policy to the WTO's dispute settlement mechanism.
} 
the new era of shared development, it is necessary to promote social fairness and justice, accelerate setting up a system to safeguard social fairness and justice, and ensure shared development as a right. International experience shows that countries falling into the middle-income trap often have widening income disparities and rising social inequality.

Development goals can only be truly achieved when the outcome of economic development benefits all people. The essence of shared development is to adhere to the people-centered development concept and to reflect the requirement of gradually achieving common prosperity. The study of shared development in this section includes three dimensions: income and wealth inequalities, equal opportunities, and the equalization of public services.

\section{B. Changes in Income Distribution}

The Gini coefficient is an important indicator to measure the income inequality of households. The closer the Gini coefficient is to 0 , the more equal the income distribution tends to be. International practice regards 0.2 or less as the absolute average income, $0.2-0.3$ as the income average, $0.3-0.4$ as a reasonable income, and $0.4-0.5$ as a large income gap. Income disparity is when the Gini coefficient reaches 0.5 or more. Figure 24 shows that although the PRC's Gini coefficient has been declining since 2009, the value is still between 0.4 and 0.5 , indicating that income inequality is relatively large. In 2016, the PRC's Gini coefficient of resident income, at 0.415, was higher than the United States.

Wealth inequality in the PRC has been lower than in the United States in recent years (Table 2). Xie and Yong'ai (2014) calculated that the Gini coefficient of household wealth in the PRC was 0.727 in 2012, and 0.700 in 2014. By contrast, the wealth Gini coefficient in the United States has been above 0.800 for many years.

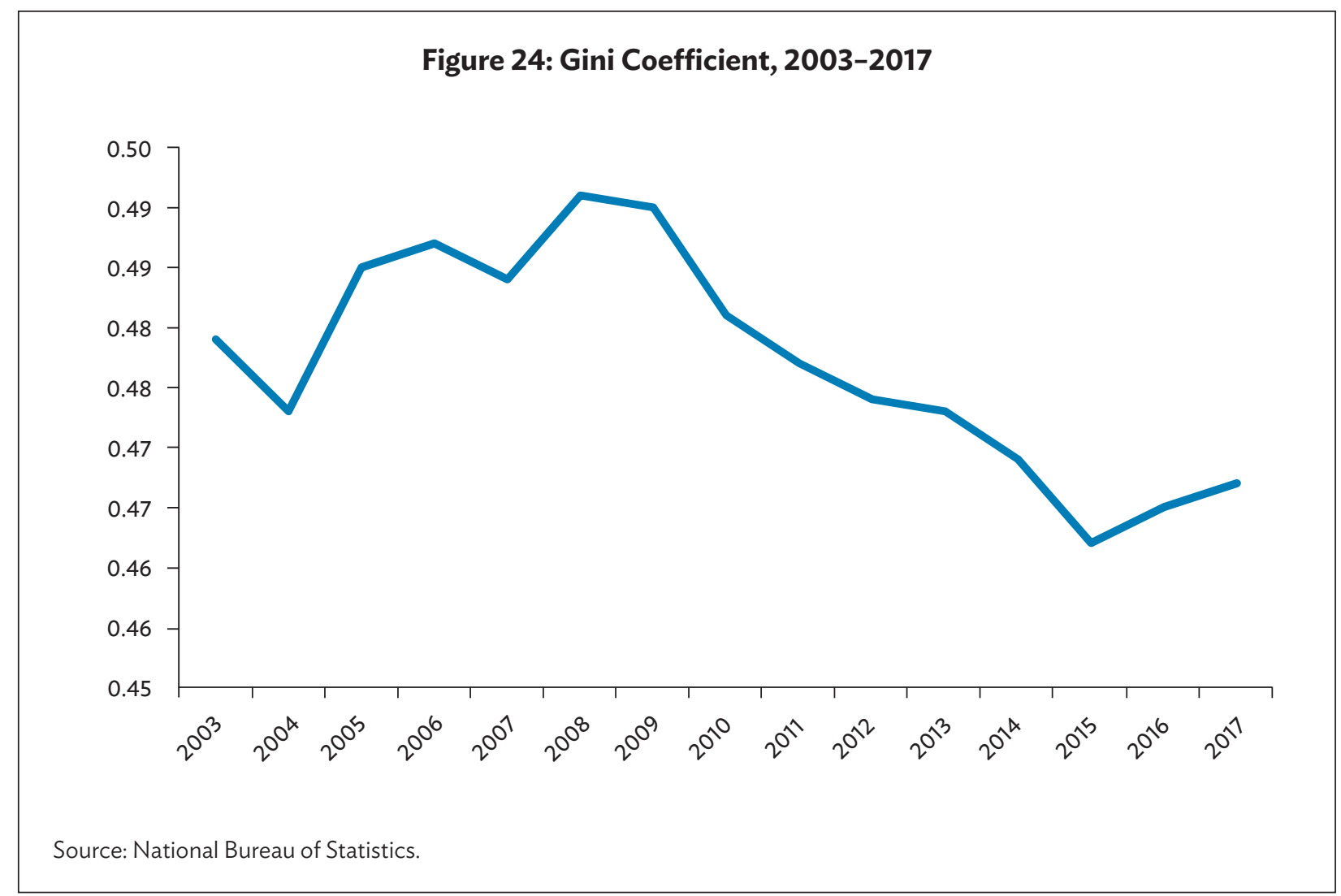


Table 2: Wealth Inequality between the People's Republic of China and the United States (\%)

\begin{tabular}{|c|c|c|c|c|c|c|c|c|c|}
\hline Country & Year & $0-40$ & $0-60$ & $60-100$ & $80-100$ & $90-100$ & $95-100$ & 99-100 & $\begin{array}{c}\text { Gini } \\
\text { Coefficient }\end{array}$ \\
\hline \multirow[t]{2}{*}{ PRC } & 2012 & 4.2 & 11.6 & 88.4 & 74.7 & 62 & 51.2 & 34.6 & 72.7 \\
\hline & 2014 & $\ldots$ & $\ldots$ & $\ldots$ & $\ldots$ & 57.7 & 46.6 & 29.7 & 70 \\
\hline \multirow[t]{6}{*}{ US } & 2001 & 0.3 & 4.2 & 95.7 & 84.4 & 71.5 & 59.2 & 33.4 & 82.6 \\
\hline & 1998 & 0.2 & 4.7 & 95.3 & 83.4 & 70.9 & 59.4 & 38.1 & 82.2 \\
\hline & 1995 & 0.2 & 4.7 & 95.3 & 83.9 & 71.8 & 60.3 & 38.5 & 82.8 \\
\hline & 1992 & 0.4 & 4.8 & 95.3 & 83.8 & 71.8 & 60 & 37.2 & 82.3 \\
\hline & 1989 & $(0.7)$ & 4.1 & 95.9 & 83.6 & 70.6 & 59 & 37.4 & 83.2 \\
\hline & 1983 & 0.9 & 6.1 & 93.9 & 81.3 & 68.2 & 56.1 & 33.8 & 79.9 \\
\hline
\end{tabular}

()$=$ negative,$\ldots=$ not available, $\mathrm{PRC}=$ People's Republic of China, US = United States.

Sources: Data on the US from Wolff (2004); data on the PRC from Xie and Jin (2014).

The Gini coefficient of household income and wealth shows the PRC has faced serious economic inequalities during the era of reform and opening-up. Indeed, the acceleration of income and property inequality before 2009 was too fast. If no effective measures are taken to reduce this phenomenon, it will seriously affect the inclusiveness of development.

\section{Equal Opportunity}

Equal opportunity is an important part of inclusive development. To some extent, its importance even exceeds the equalization of distribution results. Income mobility can be used as an indicator of equal opportunity (i.e., the higher the income mobility, the more equal is the opportunity, and vice versa). Table 3 shows the changing trends in the mobility of urban household income since the early 1990s, which reached its highest level from 1993 to 1995 and lowest from 2011 to 2013. This means the overall trend in income mobility is declining, and that stratum solidification is increasing across income groups.

The high-income mobility of urban residents in the early 1990s is inseparable from the wave of marketoriented reforms after then leader Deng Xiaoping's speech on his "southern tour" in 1992. With this opening up, opportunities to "create wealth," a large number of people started businesses, especially many on low incomes and in unstable jobs without an iron rice bowl (public sector job). Some of them became high-income earners.

Table 3: Urban Household Income Mobility (\%)

\begin{tabular}{lcccc}
\hline Degree of Mobility & 1993-1995 & 2000-2002 & 2007-2009 & 2011-2013 \\
\hline Upward mobility & 42.4 & 33.4 & 48.5 & 30.0 \\
\hline Immovable & 11.8 & 49.3 & 18.3 & 55.4 \\
\hline Downward mobility & 45.8 & 17.3 & 33.2 & 14.6 \\
\hline
\end{tabular}

Source: Yang and Shi (2016). 
The years 2000-2002 and 2011-2013 were periods when income mobility declined, but each of these periods has different characteristics. The slowing income mobility in the first period reflects a significant increase in the proportion of nonmobility, which means an increased proportion of households staying in the original income group, while the proportion of low-income groups moving upward decreased. This may have been caused by the supply of workers in the urban labor market exceeding demand because of the restructuring and downsizing of firms. During this period, a large number of laid-off and unemployed workers fell back into the low-income category in cities and towns. The declining income mobility from 2011 to 2013 mainly reflects a significant increase in the proportion of households with nonmobility of income. In this period, few high-income households moved to the low- and middle-income categories. This shows that the economic position of high-income households was further consolidated, and that their accumulated wealth is sufficient to maintain their long-term stability at the high-income level.

The income mobility of urban households recovered from 2007 to 2009 . This was reflected in the increasing proportion of upwardly mobile low-income groups and the downward mobility of highincome groups after the global financial crisis. The crisis hit some foreign-funded sectors and high-wage industries, such as securities and real estate, resulting in the decline or slower growth of wages in these sectors. At that time, the government's economic stimulus plan maintained stable employment and stimulated to some extent better wages among low-wage earners.

\section{Equalization of Public Services}

As a fundamental public service, education can break the intergenerational cycle of poverty and improve equality of opportunity. Significant gaps remain between regions in per capita spending on education. In Beijing and Shanghai, for example, this far exceeds the national average. The unequal distribution of resources for public education worsens income inequality, and is not conducive to shared development. The PRC is striving to achieve the equitable distribution of resources for public education so that students in remote rural and poor areas have access to the same quality of education opportunities as students in the big cities.

\section{E. Policy Recommendations for Promoting Shared Development}

To promote shared development, it is essential to formulate an enforceable policy system to ensure that all citizens can participate in the process of economic growth and have equal access to education, and to create a fair environment for market competition without discrimination. The following recommendations are offered to help advance the PRC's goal of shared development:

(i) Improve endowment insurance. Continue to expand the coverage of endowment insurance, improve the basic endowment insurance system, start national endowment insurance planning as soon as possible, and improve the endowment service system. For this, measures should be taken to promote the active participation of employees of small- and medium-sized enterprises, migrant workers, and people with flexible and new forms of employment to encourage and enable all kinds of entities and qualified workers to get insured. There is a growing need for improving the basic pension system for urban and rural residents, and establishing a unified public service platform for social insurance across the country. The investment and operation of endowment insurance funds need to be strengthened to maintain and increase their value. Old-age care facilities, training plans for nursing staff for the elderly, and liberalizing the pension service market should also be considered.

(ii) Strengthen public services reforms. Three areas in particular warrant attention: a stronger policy effort is needed to improve infant and childcare public services, and to actively promote labor participation, especially for women. The household registration 
system needs further reform to reduce and ultimately remove institutional barriers to labor mobility. New employment policies are needed to deal with structural unemployment.

(iii) Pursue further education reforms. Preschool education should be vigorously promoted, especially by strengthening inclusive preschool education in rural areas. Compulsory education needs to be further strengthened, and high school education made more universal, especially in poor areas in the central and western regions. Continuing education, financial assistance for students, and skills training will enable a huge number of people get a higher and perhaps lifelong education.

(iv) Gradually expand the welfare system. Shared development and common prosperity are gradual processes that will require social wealth to be expanded. It is important to get the balance right between "making a bigger cake" and "sharing the cake." When the cake is bigger, it needs to be shared fairly. A lesson some countries in Latin America and other regions learned from their prolonged stagnation in the middle-income stage was the rashness of excessive commitments to the supply of public goods that they could not fulfill.

Shared development does not merely mean sharing wealth and participating in the economy. Moreover, its coverage is not restricted poverty alleviation, inclusive finance, equal opportunities in education, social security, and more equal access of basic public services. Shared development also involves broader political and social participation. It is only with the real participation of all citizens can the concept of people-centered development be finally implemented.

\section{FIVE-YEAR PLANS USING THE 1+N APPROACH}

The PRC's five-year plans could be strengthened by shifting to the $1+\mathrm{N}$ planning mode; in broad terms, from a decentralized arrangement to a centralized one. The former is based on the initiatives proposed by each state department and locality, while the latter is based on the master plan designed by central authorities. Shifting to the $1+\mathrm{N}$ mode could be done in two stages. First, draw up a national master plan of the strategic objectives and vision for the five-year plan planning period that would be formulated by central authorities. This would be done on the basis of extensive consultation with departmental and local officials and social groups. In the second stage, after the master plan has been approved by the National People's Congress, each government department draws up a work plan that reflects not only the requirements of the master plan but also highlights the department's conditions and priorities. Under this proposal prefectures and lower-level government will no longer formulate their own five-year plans, but propose implementation plans for higher-level plans.

Here, each department and locality draws up what would essentially be a section of the five-year plan. At different stages of the planning preparation, the master plan drafting group solicits comments from departments on planning ideas, and drafts the proposals. The drafting group would be responsible for the consultations that will provide an opportunity for departments and localities to voice their interests.

A problem with the current method for drawing up five-year plans is that although they facilitate the exchange of information and opinions among different departments, it also causes serious problems, such as the "departmentalized" and fragmented formulation of these plans. This, in essence, has three worrying effects. The first is that if the contents of a plan are departmentalized and fragmented, they might not reflect national overall strategic objectives. The plans in their current form are divided into chapters and sections, most of which describe the responsibilities and tasks of a specific department. 
It is not uncommon, however, that some important national strategic objectives are not reflected in these chapters and sections. For instance, promoting employment and environmental governance are objectives that cannot be solved only by the Ministry of Human Resources and Social Affairs and the Ministry of the Environment. Instead, this requires cooperation and support from all relevant departments. The Thirteenth Five-Year Plan mainly comprises task breakdowns for each department; as a result, the plan is fragmented and does not truly reflect national overall strategic objectives.

The second effect is that with the decentralization of decision-making power and the diversification of interests, formulating five-year plans are likely to become a process in which all departments compete for administrative resources. Departments or local authorities will get more leverage in the allocation of resources and the acquisition of projects when their five-year plans are incorporated into the national one. Apart from formal channels, such as directly participating in the plan's development, a department or local authority will be able to strengthen communication with national leaders and the drafting group through various channels to reflect their own policy interests. Doing this will also reflect policy claims through indirect channels, such as the National People's Congress, the Chinese People's Political Consultative Conference, and scholars. Five-year plans need to reflect the interests and needs of all parties, but there will inevitably be conflicting interests. The department-based approach often gets in the way of the need for these plans to reflect long-term objectives and overall interests, thus weakening the very integrity and coordination of national development planning. What is more, some issues raised by departments are not conducive or are at odds with overall objectives. A result of accommodating these discussions is that they often make the five-year plan document much longer than desirable.

The third effect is that department-based five-year plans, by their fragmented nature, distort the making and implementation of policies. The National Development and Reform Commission has to strike a balance between targets and tasks that are in line with the interests of all departments and local authorities. Those that do not conform to the interests of departments and local authorities are to be implemented selectively and with flexibility. However, this can result in national strategic objectives and tasks failing to penetrate all aspects of government work, thereby distorting five-year plans and even making them unmanageable.

To deal with the problem of department-based and fragmented five-year plans, their top-level design function should be strengthened, and planning practices improved. A two-step mode for formulating five-year plans is recommended in which the central government draws up a national master plan, and each department formulates a work plan that reflects all the strategic objectives of the national master plan. Department plans, however, are part of the national master plan, and are implemented separately.

\section{A. National Master Plan}

The national master plan should embody the overall strategic vision. Based on analysis of development trends at home and abroad, it should diagnose the problems facing development and analyze any deepseated contradictions. The master plan should lay out the overall vision of national development; the main objectives to be met (balanced, inclusive, and sustainable development in the Thirteenth FiveYear Plan); and the targets and tasks that need to be undertaken to accomplish these.

The master plan should not address specific sectoral tasks, but rather guide and support sector planning. The division of chapters and sections should be determined by strategic objectives and implementation steps, not by government departments. The master plan should be formulated by the Party Central Committee and State Council after extensive consultation. Their inputs should be used as a basis for reference, but not the foundation of the plan's sections. 


\section{B. Department and Local Work Plans}

The master plan, on completion, is submitted to the National People's Congress for deliberation and adoption. Guided by the master plan, government departments and localities would then propose their own five-year work plan to achieve the strategic goals of the national master plan-and not just those that affect their own needs and priorities. For example, industry regulators need to think about employment and environmental protection, the agriculture authority needs to think about new forms of urbanization. The environmental protection authority needs to think about job growth. And the financial authority needs to think about employment and environmental protection.

Department work plans should be approved by the State Council. The formulation of department work plans should be linked with the national master plan in terms of targets and tasks, and countersigned by relevant departments according to the division of labor and approved by the State Council before they are adopted and implemented. This is to ensure that they reflect the tasks of the master plan.

For the local work plan, the current four-level system of master planning should also be changed. Indeed, because of the PRC's large geography and regional characteristics, provincial governments need to formulate their own five-year plans according to the tasks of the national master plan. And each provincial department also needs to formulate a corresponding work plan. Under this proposed system, municipal governments would no longer have to formulate five-year plans, and if necessary, they only need to make implementation plans for the five-year plans designed by higher-level authorities. In other words, instead of proposing their own master plans, prefecture and county authorities should focus on implementing national and provincial plans.

Department and local work plans should be coordinated with proper financial arrangements. The compilation, implementation, and evaluation of department and/or local plans should be combined with the management of fiscal budgets and final accounts, as well as with reforms that are compatible with administrative and financial responsibilities. Financial resources should be allocated according to the division of planned tasks and the priority direction of planned public services. The performance of government departments and localities should also be evaluated according to the evaluation results of the implementation of the plan. In other words, a $1+\mathrm{N}$ new planning model.

In conclusion, it will be difficult to adapt the current method of formulating five-year plans to the needed strengthening of the top-down, general strategic plan to advance socioeconomic development. The proposal for a new approach to formulate these plans will help achieve real synergies among departments that will deliver development benefits beyond the planning process itself. 


\section{REFERENCES}

BP. 2016. Statistical Review of World Energy 2016. London.

H. Chenery, S. Robinson, and M. Syrquin. 1986. Industrialization and Growth: A Comparative Study. New York: Oxford University Press.

G. Grossman and A. Krueger. 1995. Economic Growth and the Environment. Quarterly Journal of Economics. 110 (2). pp. 353-77.

Y. Hao, W. Ling'ou, and W. Y. Rui. 2018. Forecast and Prospect of China's Energy Economy in the New Era. Journal of Beijing University of Technology. Issue 2.

Y. Lin. 2014. New Structural Economics: A Theoretical Framework for Rethinking Economic Development and Policy. Expanded edition. Beijing: Peking University Press.

M. Olson. 2000. Power and Prosperity. New York: Basic Books

L. Shen et al. 2015: Scenario Forecast of China's Energy Consumption in 2050. Journal of Natural Resources. 30 (3).

Thomson Reuters. 2014. The Research and Innovation Performance of the G20. 10 April 2014.

E. N. Wolff. 2004. Changes in House Wealth in the 1980s and 1990s in the US. In International Perspectives on Household Wealth. Cheltenham, United Kingdom: Edward Elgar.

World Bank. World Development Indicators. http://datatopics.worldbank.org/world-developmentindicators/.

Y. Xie and J. Yong'ai. 2014. Family Property. In People's Livelihood Development Report 2014. Beijing: Peking University Press.

S. Yang and L. Shi. 2016. Urban Household Income Mobility in Urban China. Chinese Journal of Population Science. Issue 5. pp. 78-89. 


\section{Toward High-Quality Development in the People's Republic of China}

This paper covers three areas that will be vital for the People's Republic of China (PRC) to transition to high-quality development: advancing institutional reform, practicing the new development philosophy, and changing the approach to how the country's five-year plans are drawn up. For the PRC's five-year plans, the paper proposes a new top-down approach in which government departments and regional authorities contribute to national goals rather than the current practice of framing national master plans in terms of the individual goals of these entities.

\section{About the Asian Development Bank}

ADB is committed to achieving a prosperous, inclusive, resilient, and sustainable Asia and the Pacific, while sustaining its efforts to eradicate extreme poverty. Established in 1966, it is owned by 68 members49 from the region. Its main instruments for helping its developing member countries are policy dialogue, loans, equity investments, guarantees, grants, and technical assistance. 